\title{
Hydrocarbon reservoir development in reef and shoal complexes of the Lower Ordovician carbonate successions in the Tazhong Uplift in central Tarim basin, NW China: constraints from microfacies characteristics and sequence stratigraphy
}

\author{
Ngong Roger Ngia ${ }^{1,2,3,4} \cdot$ Mingyi Hu${ }^{1,3,4} \cdot \mathrm{Da} \mathrm{Gao}^{1,4}$
}

Received: 13 January 2020 / Accepted: 12 June 2020 / Published online: 23 June 2020

(c) The Author(s) 2020

\begin{abstract}
The analyses of hydrocarbon reservoirs in the high-frequency reef and shoal facies of the Lower Ordovician carbonate successions in the Penglaiba Formation $\left(\mathrm{O}_{1} \mathrm{P}\right)$ and Yingshan Formation $\left(\mathrm{O}_{1-2} \mathrm{Y}\right)$ in the Tazhong (Katake) Uplift in central Tarim basin showed three types of hydrocarbon reservoirs: type 1 associated with synsedimentary facies, type 2 developed by hot active basinal dissolution fluids [mesogenetic fluids, geothermal/hydrothermal fluids and thermochemical sulfate reduction-related fluids] and tectonic activity, and type 3 are hypogenic-epigenetic karst reservoirs formed by meteoric and mesogenetic dissolution fluids. Porosity and permeability development in the reef and shoal facies in the highstand system tracts (HST) of the third-order sequence cycles (SQ1-SQ3) correlates well with regression peaks in $\mathrm{O}_{1} \mathrm{P}_{\text {and }} \mathrm{O}_{1-2} \mathrm{Y}$, mostly related to multiphase tectonic activity, long-term exposure, denudation and dissolution in near-surface to shallow burial settings. The carbonate successions in the $\mathrm{O}_{1} \mathrm{P}$ and $\mathrm{O}_{1-2} \mathrm{Y}$ are composed of seventeen microfacies (MF-1 to MF-17) deposited on a shallow marine platform. Six main groups of microfacies associations (MFA-1 to MFA-6) were recognized, with each microfacies association corresponding to the transgressive system tracts and HST of SQ1-SQ4 in $\mathrm{O}_{1} \mathrm{P}$ and $\mathrm{O}_{1-2} \mathrm{Y}$. The microfacies represent specific sedimentary environment including platform interior and platform margin deposited under particular hydrodynamic conditions. Tectonics and frequent relative sea-level fluctuation associated with rapid transgression and slow regression favored the deposition of the large-scale vertical stacking, high-frequency reef and shoal facies across the carbonate platforms in this uplift. The hydrocarbon reservoirs in this study have relatively moderate porosity and low permeability, and are somewhat potential reservoirs for hydrocarbon exploration in the Tazhong Uplift.
\end{abstract}

Keywords Microfacies · Tazhong Uplift · Tarim basin · Lower Ordovician · Vug-fractured karstic reservoirs

\section{Introduction}

Ngong Roger Ngia

ngongrogerngia@yahoo.com

Mingyi $\mathrm{Hu}$

humingyi65@163.com

1 Sedimentary Basin Research Center, Yangtze University, Wuhan 430100, China

2 Department of Geology, University of Buea, P.O. Box 63, Buea, Southwest, Cameroon

3 Hubei Cooperative Innovation Center for Unconventional Oil and Gas, Wuhan 430100, China

4 Key Laboratory of Exploration Technologies for Oil and Gas Resources of the Ministry of Education, Yangtze University, Wuhan 430100, China
The Tarim basin in Northwest China is the largest oil-bearing basin in China (Fig. 1), where a number of oil and gas fields were recently discovered, with ongoing production in the Ordovician carbonate successions (Li et al. 1996,2012; Zhang et al. 2007). The Lower Paleozoic carbonate strata in the Tarim basin have experienced multiphase diagenetic history from early shallow marine to deep burial (Guo et al. 2016; Jiang et al. 2016), and because they are deeply buried (generally $>8000 \mathrm{~m}$ ), their primary porosities are almost totally obliterated. This basin is characterized by a long history of deposition, thick carbonate succession in the Cambrian and Ordovician Formations, complex tectonic history and abundant hydrocarbon resources (Fan et al. 2007; Li 


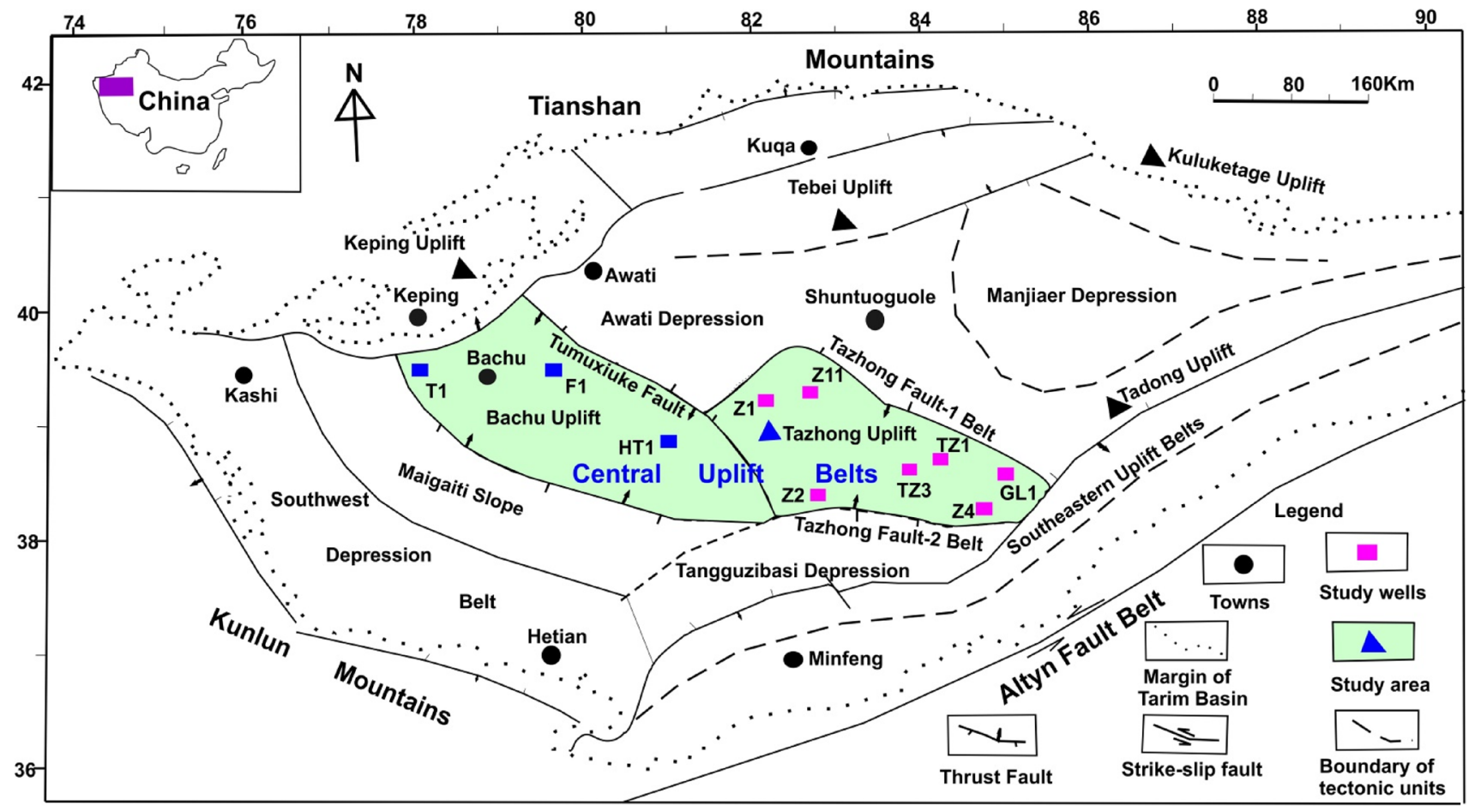

Fig. 1 A schematic tectonic map of the Tarim basin showing the distribution of structural units within the basin and the location of wells in the Tazhong (Katake) Uplift (Lin et al. 2009)

et al. 2012; Gao and Fan 2014b). Studies have been done on the Lower Ordovician carbonate reservoirs in the Tazhong area of the Tarim basin (Yang et al. 2011; Wu et al. 2012; Zhao et al. 2012). Shallow marine carbonate reservoirs have also been the focus of petroleum exploration and development in this basin (Yang et al. 2011; Lan et al. 2013; Fu et al. 2017). The primary porosity and permeability are commonly reduced by intensive compaction and cementation, and secondary porosity is thought to play a major role as productive reservoir spaces in the shallow-deeply buried carbonate rocks in the Tarim basin (Zhang et al. 2009). The secondary porosity in these carbonate rocks are often related to early, near-surface diagenetic processes and tied to subaerial exposure and freshwater dissolution, and under shallow-deep burial conditions through dissolution by mesogenetic fluids, thermochemical sulfate reduction and hydrothermal fluid activity (Cai et al. 2001, 2008, 2009a, b, 2015a, b, 2016; Yang et al. 2012; Li et al. 2014; 2016; Zhu et al. 2015; Jiang et al. 2015, 2016; Liu et al. 2017). Recently, researchers have been increasing interest in structurally controlled hydrothermal dolomitized rocks for their potential as favorable reservoirs (Dong et al. 2016; Hendry et al. 2015; Zhu et al. 2015; Jiang et al. 2015; Li et al. 2016). Recent exploration has confirmed that huge hydrocarbon resources can be found in these Lower Paleozoic ancient dolomite reservoirs (Cai et al. 2002, 2009a, b, 2015a; Wang et al. 2014). The deeply buried Cambrian dolomites in the
Tarim basin are reported to contain significant hydrocarbon resources as a result of localized to widespread source rocks in the Lower Cambrian strata (Cai et al. 2009a, b, 2015b, Zhao et al. 2013), as well as thick, regional anhydrite seal deposits in the Middle Cambrian strata (Wang et al. 2014; Cai et al. 2015a), which is an indication of high prospects for future hydrocarbon discoveries.

Research on carbonate platforms in Tarim basin have been focused on sedimentary environment (Feng et al. 2007; Hu et al. 2009), sequence stratigraphy (Zhang and Liu 1995), and reef and shoal distribution (Gao and Fan 2015; Yang et al. 2011) in the Ordovician carbonate succession. High-energy environments such as platform margin reef and shoals, and intraplatform shoals in the Tarim basin are considered as the most important areas for petroleum exploration. Recently, research has been done on the development of layered deposits and the distribution of reservoirs on platform margin reef and shoals and intraplatform shoal facies (Gu 2001; Gao and Fan 2015). The depositional cycle architecture of the Lower Ordovician depends on the environmental factors that change periodically causing rapid and progressive facies changes with time. Goldhammer et al. (1993), Gonzales (1996) and Chen et al. (1999) have done research on the effects of high-frequency relative sea-level changes in carbonates successions and revealed that depositional cycles are excellent indicators of sea-level fluctuations since their development depend on many variable factors. 
Microfacies analysis in carbonate rocks and the interpretation of sedimentary environments have been a fundamental research area for researchers (Wilson 1975; Flügel 2004; Gao et al. 2014). Understanding the patterns of microfacies successions and the influence of sequences stratigraphy on carbonate platforms is vital in predicting favorable hydrocarbon reservoirs (Al-Awwad and Collins 2013; Li et al. 2013a, b). However, little attention has been paid to the variation in microfacies and microfacies associations in the Lower Ordovician carbonate successions in the $\mathrm{O}_{1} \mathrm{P}$ and $\mathrm{O}_{1-2} \mathrm{Y}$ and the development of hydrocarbon reservoirs in high-energy reef and shoal facies.

This paper aims to: (1) study the development of favorable hydrocarbon reservoirs in the high-energy reef and shoal complexes, (2) elucidate microfacies characteristics and their sedimentary environments, and (3) attempt an interpretation of the coarsening-upward depositional sequence cycles in the Lower Ordovician Formations in the Tazhong Uplift in central Tarim basin. This interval of the Ordovician period is chosen because it represents a depositional sequence that reveals lithofacies alternations with successive and repeated coarsening-upward trends.

\section{Tectonostratigraphic settings}

The Tazhong Uplift is located in the Central Uplift Belt of the Tarim basin (Fig. 1). The deeply buried Lower Ordovician carbonates in the Tazhong Uplift have suffered multiphase episodes of intense tectonic activity during the Caledonian and early-late Hercynian orogeny (Wu et al. 2012). The Tazhong Uplift is a paleo-uplift that developed as a result of the effect of compressive stress on the Late Cambrian-Early Ordovician carbonate strata (Gao and Fan 2014a; Ngia et al. 2019; Hu et al. 2019). This paleo-uplift stretches for more than $300 \mathrm{~km}$ from east-west, $80-100 \mathrm{~km}$ wide, and it is bounded by the Tazhong fault- 1 in the north and Tazhong fault-2 in the south (Lin et al. 2012). The fault structures in this paleo-uplift mainly developed in the Lower and Middle Paleozoic, and consist of fold-fault structural belt. A series of NW-SE-, NWW-SEE- and NE-SW-trending reverse faults, and NE-SW-trending strike-slip faults (Gao and Fan 2014a, b; Li et al. 2013a, b) developed in the Tazhong Uplift and led to the Tazhong block compartmentalization (Gao and Fan 2014a, b). A series of half-grabens and normal faults developed during Early-Middle Cambrian, indicating that the Tarim craton was a divergent rifted continental margin characterized by fault-related depressions (Gao and Fan 2014a, b). In plain view, the faults controlling half-graben deposition exhibit four patterns such as relay, en-echelon, parallel stripe and quasi-arch types (Li et al. 2013a, b). Relaypatterned faults are associated with a range of parallel, discontinuous and overlapping structural units and are common in the Tazhong area ( $\mathrm{Li}$ et al. 2013a, b; Gao and Fan 2014a, b). En-echelon faults form near-vertical strike-slip structures and exhibit flower structures in vertical profile in central Tarim basin ( $\mathrm{Li}$ et al. 2013a, b). The latter two types only occur locally in the Tazhong area. The multiphase episodes of intense tectonic activity in the Tazhong Uplift during the Caledonian and early-late Hercynian orogeny (Wu et al. 2012) could have exerted substantial influence on the deeply buried Cambrian carbonate rocks as they were penetrated by the intrusive diabases and volcanic eruptive edifice through geothermal/ hydrothermal fluid inputs (Chen et al. 1997; Jiang et al. 2015; Guo et al. 2016; Ngia et al. 2019). As a result, conjugate fault systems and related fracture networks were created in the Cambrian to Lower Ordovician sedimentary packages particularly in the Tazhong area. The Tazhong Uplift lies between the Tangguzibasi Depression and Manjiaer Depression (Fig. 1). A series of tectonic activities during the Lower and Middle Ordovician in the Tazhong Uplift (Gao and Fan 2014a, b; Li et al. 2013a, b; Hu et al. 2019) resulted in three unconformities (RUS1, RUS2 and RUS3) as the lower, middle and upper boundaries of the Lower Ordovician Formations (Lin et al. 2012). Relative sea-level fluctuation during the Lower Ordovician period in the Tazhong Uplift resulted in the development of vertical stacking sedimentation on the carbonate platform (Liu et al. 2006).

On the basis of petrographic characteristics and biofacies, the Lower Ordovician sedimentary environments and lithofacies could be summarized as follows: Restricted platform depositional facies during the Lower Ordovician include intertidal-supratidal and shallow subtidal-tidal flat or lagoon shoal facies over a wide area in the Tazhong Uplift (Fig. 2). The open platform developed partly during the Lower Ordovician and fully during the Middle Ordovician in both the northern and southern parts of the Central Uplift Belt, and is composed of intraplatform shallow subtidal-intertidal sand shoal facies (Gao and Fan 2015). A short regression phase at the end of the Lower Ordovician resulted in local erosion during the Late Yingshan Formation (Liu et al. 2006; Lin et al. 2012). Platform margin deposits were formed throughout the Lower Ordovician period in the Tazhong Uplift forming a wide facies belt around the Central Uplift Belt. The platform margin extended laterally on both sides of the Central Uplift due to high carbonate production rate and continual deepening of the platform during marine transgression (Zhao et al. 2007). Biostratigraphically, the stratigraphic subdivision of the Lower Ordovician strata in the Tazhong Uplift is based on the study of conodont species (Zhao et al. 2006; Jing 2009) commonly found preserved in platform carbonate rocks (Fig. 3a). 


\section{Data and methods}

In total, 290 rock samples and cores were obtained from eight wells and the detailed petrographic examination of 210 thin sections, with some stained with Alizarin Red S to differentiate calcite from dolomite, was carried out by petrographic microscope in the Key Laboratory of Exploration Technologies for Oil and Gas Resources, Yangtze University.

The reservoir property data (permeability and porosity) of over 170 samples were measured with permeability and porosity analyzers (MFA-170 and SMP-200). Carbonate microfacies were described following the classification of Dunham (1962) with the modifications of Embry and Klovan (1971), Wilson (1975) and Flügel (2004). A combined detailed analysis of well log (gamma log and resistivity log readings), core data and petrographic studies were carried out in order to analyze the microfacies in the thick coarsening-fining-upward sequences of the Lower Ordovician carbonate succession in the Tazhong Uplift. We established a sedimentary model for the Lower Ordovician carbonate successions to identify the intervals of depositional facies on the carbonate platforms.
Fig. 3 a Depositional sequence cycles of the Lower Ordovician carbonate successions in the Tazhong Uplift, central Tarim basin. b Depositional sequence cycles and well log-based correlation of the Lower Ordovician carbonate successions in the Tazhong Uplift, central Tarim basin. c Asymmetrical and symmetrical depositional sequence cycles of the Lower Ordovician carbonate successions in the Tazhong Uplift, central Tarim basin. Points B, D, F, H and J constitute the HST and represent repeated asymmetrical coarsening-upward depositional cycles, and points A, C, E, G, I and K constitute the TST and represent gradual facies transition between small-scale symmetrical depositional cycles. Note that the thick red cycle on point D in SQ2 in $\mathrm{O}_{1} \mathrm{P}$ indicates the brecciated bioclastic limestone

\section{Results}

\section{Characteristics and depositional sequence cycles of the Lower Ordovician carbonate successions}

The Lower Ordovician carbonate successions in the Tazhong Uplift are characterized by vertical stacking pattern, cyclic sequences that are successively and somewhat progressively coarsening-upward, with various facies in the cycles having variable thickness, erosional and flooding surfaces. Six third-order sequences are recognized in these carbonate successions in the Tazhong Uplift. They are determined on the basis of well drilling data, cores and evidence from subaerial exposure events in the facies stacking patterns. The

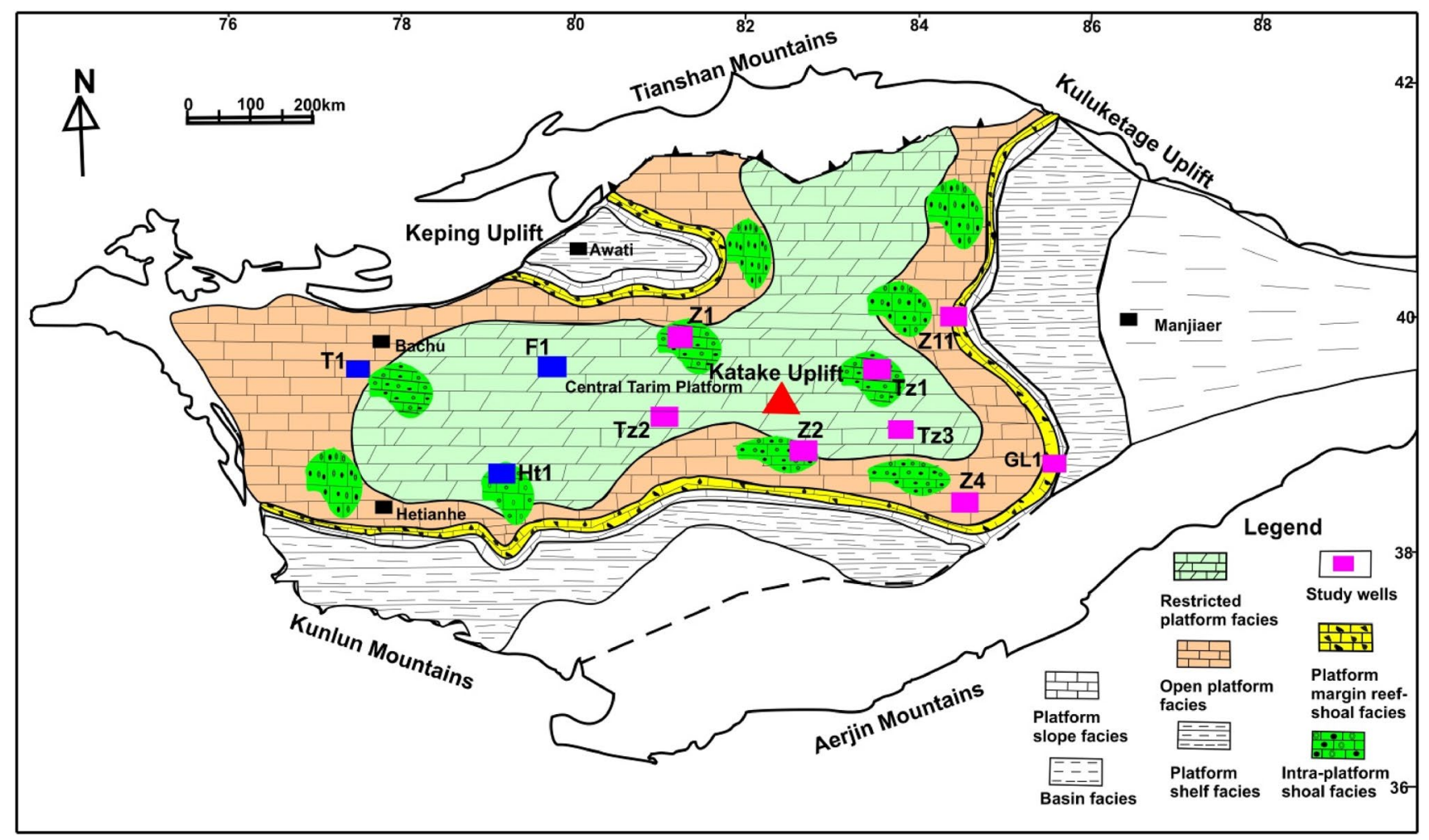

Fig. 2 Paleogeography and sedimentary facies of the Lower Ordovician in the Tazhong Uplift in central Tarim basin: note the location of the study wells on the carbonate platform in the central parts of the basin. (Modified from Gao and Fan 2014a, 2015) 
a

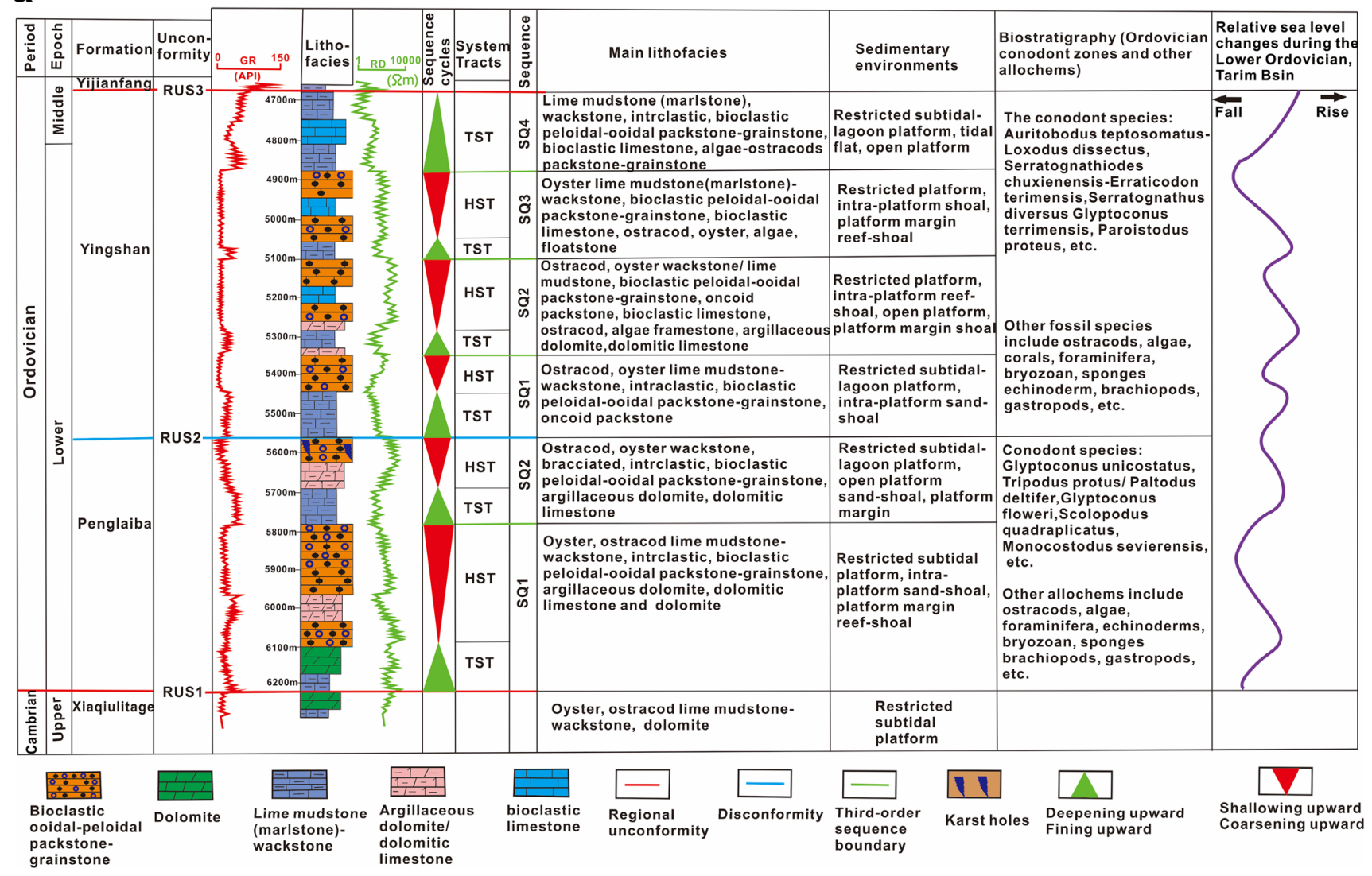

b

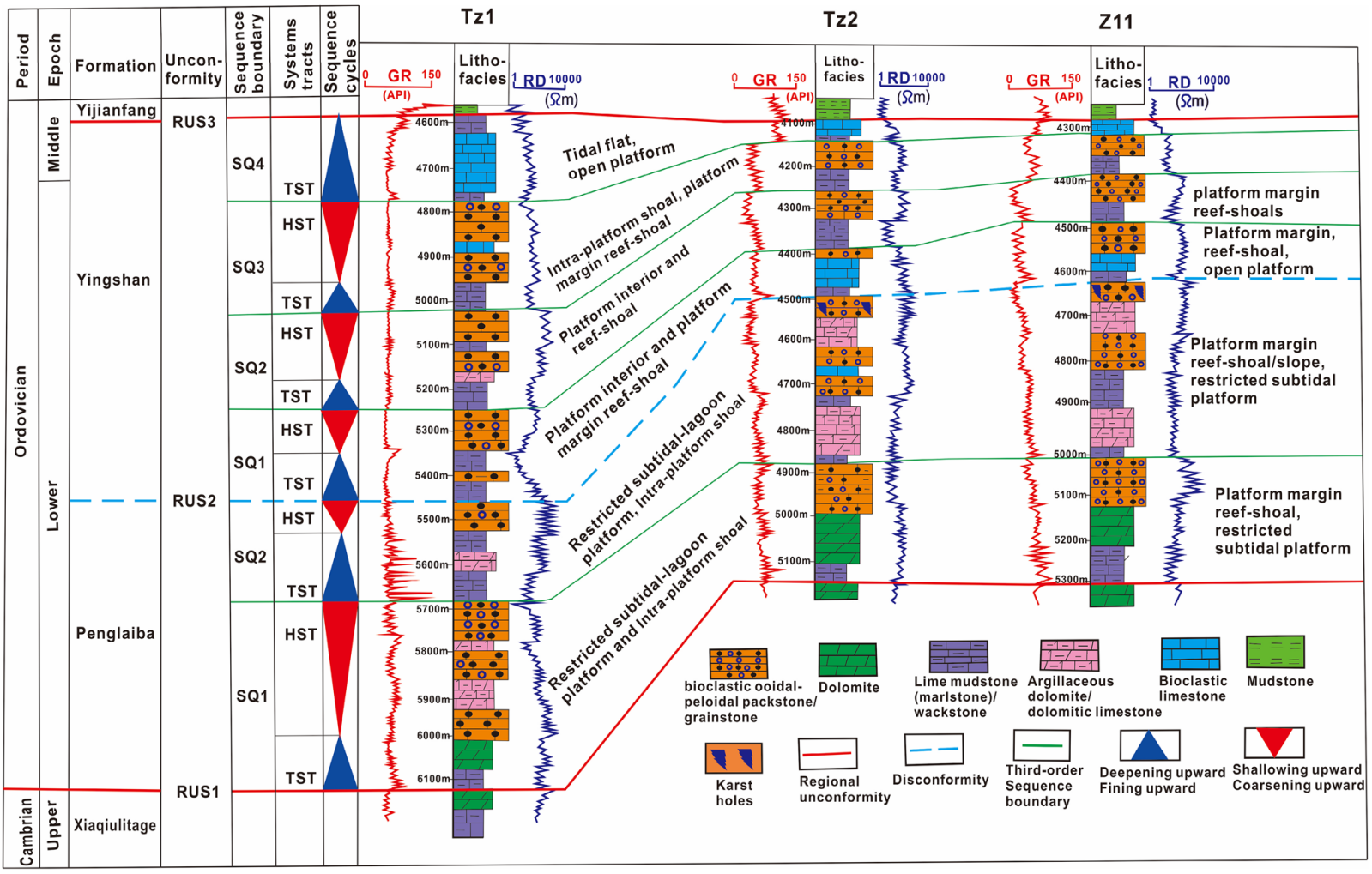



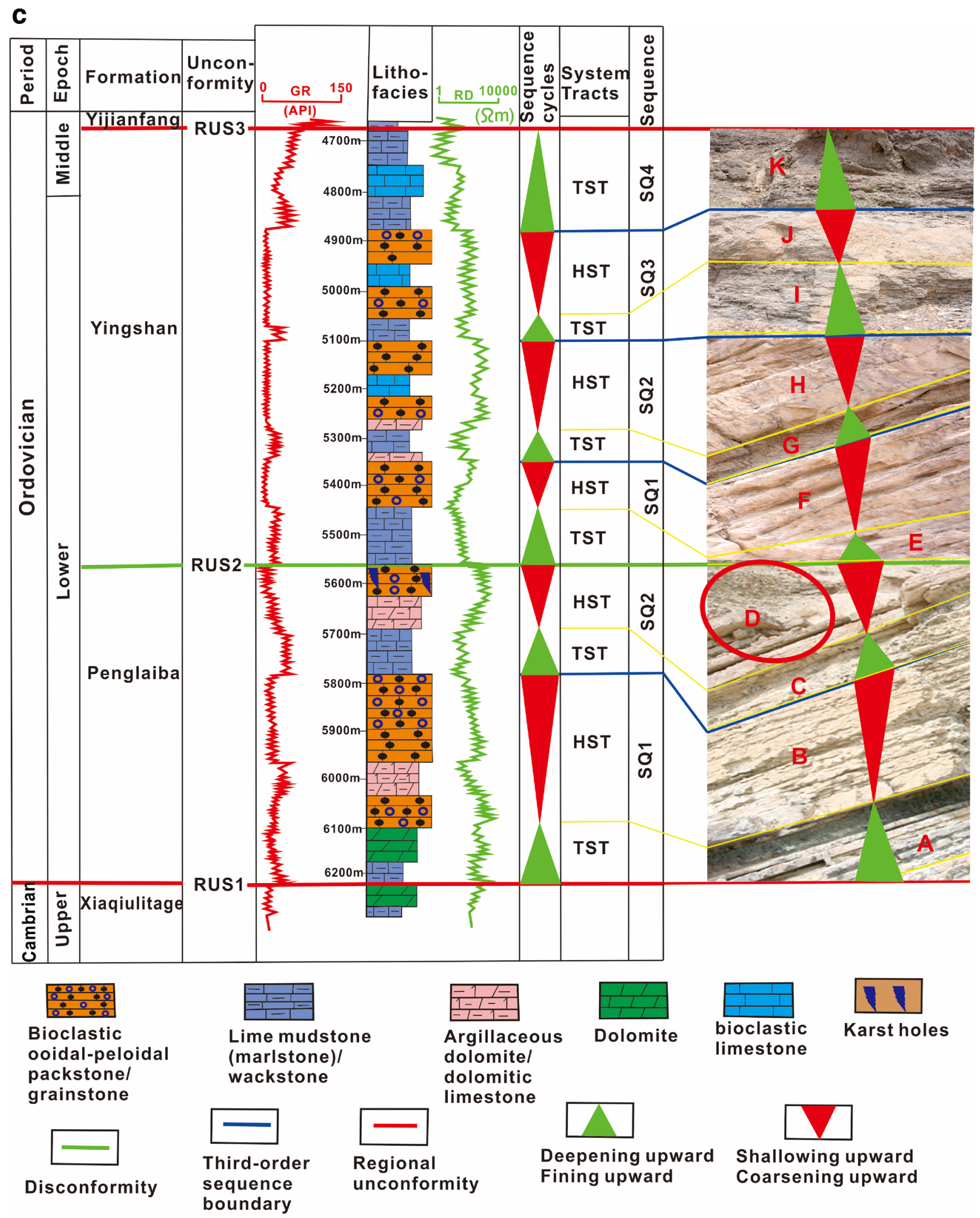

Fig. 3 (continued) 
third-order sequences (SQ1-SQ4) contain both transgressive system tracts (TST) and highstand system tracts (HST) (Fig. 3a, b).

\section{Characteristics and depositional sequence cycles of the Penglaiba Formation}

The $\mathrm{O}_{1} \mathrm{P}$ can be divided into two third-order depositional sequences (SQ1 and SQ2), which contains both the TST and HST (Fig. 3a, b). Based on facies changes across sequence boundaries within cyclic strata in the $\mathrm{O}_{1} \mathrm{P}$, asymmetrical and minor symmetrical meter-scale depositional cycles were identified (Fig. 3c). The asymmetrical cycles are dominant and are characterized in some places by lapse in facies deposition across the cyclic boundaries (Fig. 3c; points $\mathrm{B}$ and $\mathrm{D}$ ). The symmetrical cycles are less common and show gradual microfacies transition across the boundaries within the cyclic strata (Fig. 3c; points A and C) (Chen et al. 1999,2018).

The microfacies in the lower cycle of the shallowing-upward and coarsening-upward, meter-scale cyclic sequence (SQ1) are composed of crystalline dolomites, bioclastic lime mudstones (marlstones)-wackestones, dolomitic limestone and argillaceous dolomite, constituting the TST (Fig. 3a-c). The microfacies in the upper cycle of the HST of SQ1 include coarse-grained bioclastic ooidal-peloidal packstone-grainstone and bioclastic floatstone. The thickness of the lower cycle microfacies varies in different intervals and ranges from 80 to $140 \mathrm{~m}$, whereas that of the upper cycle microfacies ranges from about $85-290 \mathrm{~m}$. On the other hand, the microfacies in the lower cycle of the TST of SQ2 are composed of lime mudstones (marlstones), ostracod-oyster wackestone-packstone, argillaceous dolomite and dolomitic limestone. The HST represents the coarse-grained upper cycle microfacies (Fig. 3a, b). The thickness of the lower cycle microfacies varies in different intervals and range from 70 to $175 \mathrm{~m}$, and that of the upper cycle range from about 45-195 m. Bioturbation occurs locally within the bioclastic lime mudstone (marlstone)-wackestones facies with clasts of bioclastic ooids and peloids common (Fig. 4e).

The microfacies in the lower and upper cycles in the SQ1 and SQ2 of the $\mathrm{O}_{1} \mathrm{P}$ Formation are separated at their bottom by conspicuous erosional surfaces (Fig. 4b, c, f). Ooids and peloids with numerous bioclasts oriented parallel to beddings are observed and are considered as deposits from unidirectional tidal and storm surge flow (Fig. 4b, c, f). The topmost part of SQ2 is a surface of unconformity (RUS2) (Fig. 3a-c). Below the surface of the RUS2 unconformity in the $\mathrm{O}_{1} \mathrm{P}$ are karst breccia (Fig. 4f, g), which may have developed at the base of a talus slope on the platform margin or probably associated with erosion, burial dissolution, faulting activity and collapse filling of karst caves in the weathered karst belt (Fig. 3a-c) (Gong and Liu 2003; Baryakh and Fedoseev 2011).

The microfacies of the SQ1 and SQ2 in the $\mathrm{O}_{1} \mathrm{P}$ are characterized by relatively low-medium gamma-ray readings throughout (Fig. 3a, b), which reflect medium-highenergy depositional conditions in restricted shallow marine subtidal-intertidal platform and platform margin reef and shoals.

\section{Characteristics and depositional sequence cycles of the Yingshan Formation}

On the basis of well logging and core data, the thickness of the $\mathrm{O}_{1-2} \mathrm{Y}$ ranges from 300 to $700 \mathrm{~m}$ (Jianfa et al. 2015). This formation is divided in to four third-order sequences (SQ1-SQ4), which contains both the TST and HST (Fig. 3a-c). This formation is mostly characterized by shallow subtidal-intertidal depositional cycles comprising of deep subtidal fine- to medium-grained microfacies at their base and shallow subtidal to intertidal coarse-grained microfacies toward the top of the sequence, representing incomplete shallowing subtidal-intertidal aggradational facies stacking patterns. In addition, the facies changes across the sequence boundaries within cyclic strata constitute meterscale asymmetrical and minor phases of symmetrical cycles (Fig. 3c).

The microfacies of the lower cycle of the TST of SQ1 in the $\mathrm{O}_{1-2} \mathrm{Y}$ are lime mudstone (marlstones)-wackestone. The microfacies in the upper cycle are regarded as the HST of SQ1 and comprise intertidal-supratidal coarse-grained microfacies (Fig. 3a, b). The thicknesses of the finingupward lower cycle microfacies vary in different places and intervals, and range from about 40-95 m, whereas those of the coarse-grained upper cycle microfacies range from 40 to $70 \mathrm{~m}$.

The lower cycle microfacies in the TST of SQ2 are composed of argillaceous dolomite and dolomitic limestone interbedded with bioclastic lime mudstones-wackestones (Fig. 3a). The bioclastic lime mudstones (marlstones) somewhat contains nodules, with argillaceous-calcareous sediments infills around the nodules, reflecting deposition in a low-energy environment. The coarse-grained upper cycle members correspond to the HST of SQ2 and comprise mixed microfacies (Fig. 3a). The maximum flooding surface of this sequence is characterized by bioclastic lime mudstones (marlstones)-wackestones. The thickness of the deepening-upward and fining-upward lower cycle microfacies varies in places and ranges from about $20-60 \mathrm{~m}$, and that of the coarse-grained, coarsening-upward upper cycle microfacies ranges from about $40-97 \mathrm{~m}$.

The SQ3 constitutes the upper part of the $\mathrm{O}_{1-2} \mathrm{Y}$ (Fig. 3a, b) and begins with interbedded bioclastic lime mudstone-wackestone as the lower cycle microfacies,

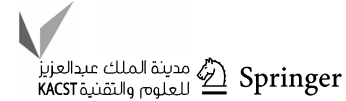



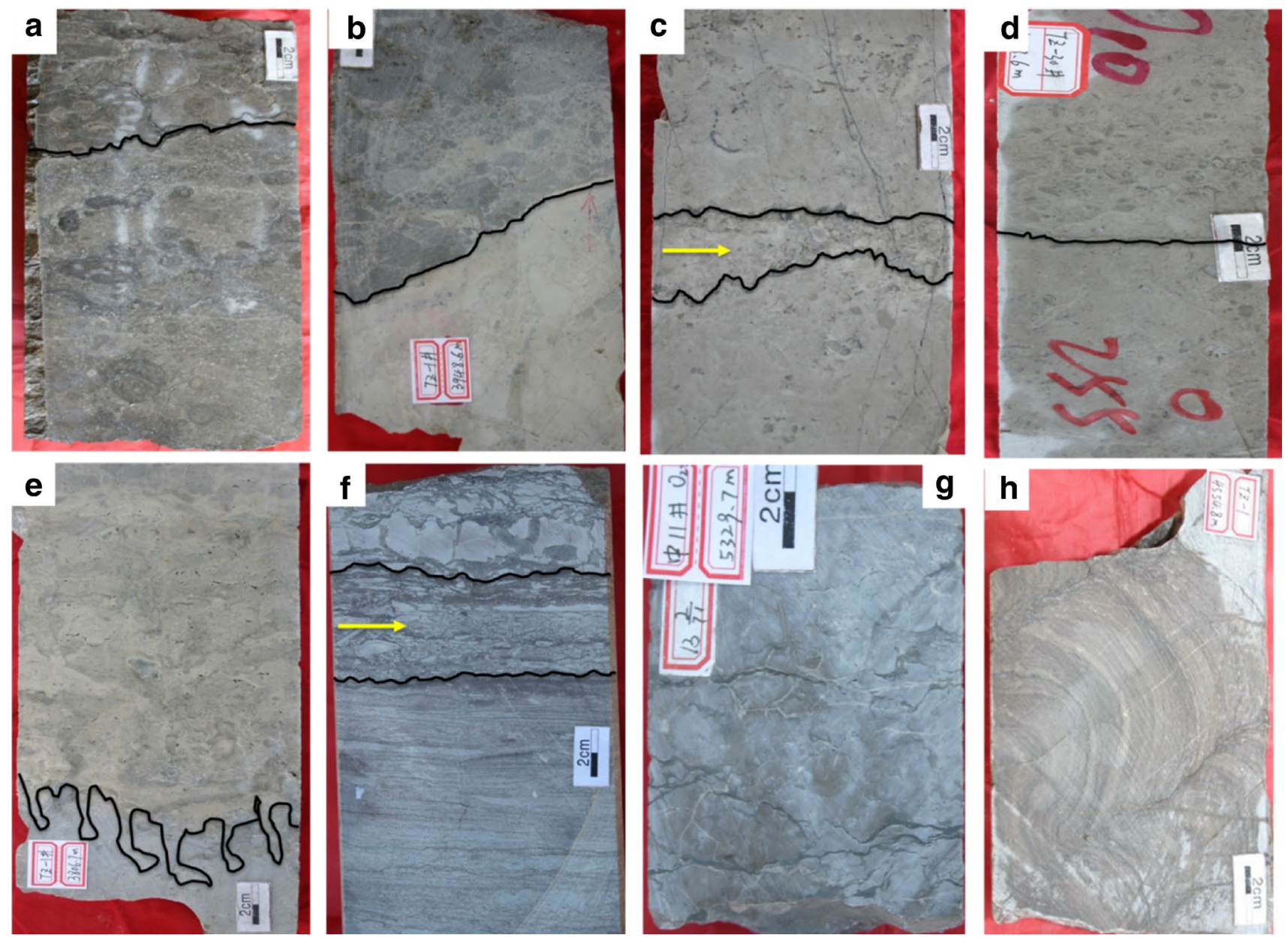

Fig. 4 Core photographs of the reef and shoal facies showing: a bioclastic oncoidal packstone (MF-1), overlying lower intraclastic ooidal grainstone and are separated by low-amplitude stylolite; $\mathbf{b}$ bioclastic peloidal grainstone (MF-14) lying unconformably on bioclastic paloidal wackestone bed (MF-13); c upper lime mudstone-wackestone bed (MF-7), truncated by bioclastic ooidal-peloidal grainstone (MF-10), separated by erosional surfaces; $\mathbf{d}$ intraclasts, bioclastic peloidal packstone (MF-9), overlying peloidal wackestone bed (MF12), truncated by an erosional surface; e bioturbated peloidal wack-

constituting the TST of the sequence. The maximum flooding surface of the SQ3 is characterized by the upper part of the bioclastic lime mudstone-wackestone bed. The microfacies in the HST of SQ3 include medium-thick-bedded bioclastic ooidal-peloidal packstones-grainstones and ostracod-oyster-algae floatstone interbedded with bioclastic limestone. The thickness of this sequence ranges from about $20-65 \mathrm{~m}$ for the fine-grained lower cycle microfacies and $45-145 \mathrm{~m}$ for the coarse-grained upper cycle microfacies (Fig. 3a, b). The increase in mud content at the topmost part of SQ3 reflects the start of the drowning process of the carbonate platform. The microfacies of SQ1-SQ3 are characterized by relatively low-medium gamma-ray readings (Fig. 3a, b) throughout and reflect moderate-high

stone (MF-12), with worm burrow infilled with overlying wackestone materials; $\mathbf{f}$ brecciated, bioclastic, peloidal packstone (MF-8), lying unconformably on unidirectional bioclastic ooidal-peloidal granstone (MF-10), which in turn unconformably overlay laminated lime mudstone-wackstone bed (MF-7); g brecciated bioclastic peloidal packstone (MF-8), with irregular fractures and stylolites filled with sparry calcite cement; $\mathbf{h}$ dome-like stromatolitic microbialite fabric, regular dark-colored laminae and light-colored micrite and microspars are distinct

hydrodynamic sedimentary conditions on platform margin and platform interior.

The shallowing-upward subtidal-intertidal cycles in this formation are typically asymmetrical cycles exhibiting both thickening and coarsening-upward trends (Fig. 3c; points $\mathrm{F}, \mathrm{H}$ and $\mathrm{J}$ ), and reflect a prolong marine regression and upward increase in hydrodynamic conditions that are usually controlled by relative sea-level fluctuation (Chen et al. 1999; Zhu et al. 2017). The minor symmetrical cycle phases in this formation constitute the lower cycle microfacies of the sequences (SQ1-SQ4) (Fig. 3c, points E, G, I and K). The topmost part of this formation (e.g., TST) belongs partly to the Dapingian Stage of the Middle Ordovician period which is considered as a drowning-upward 

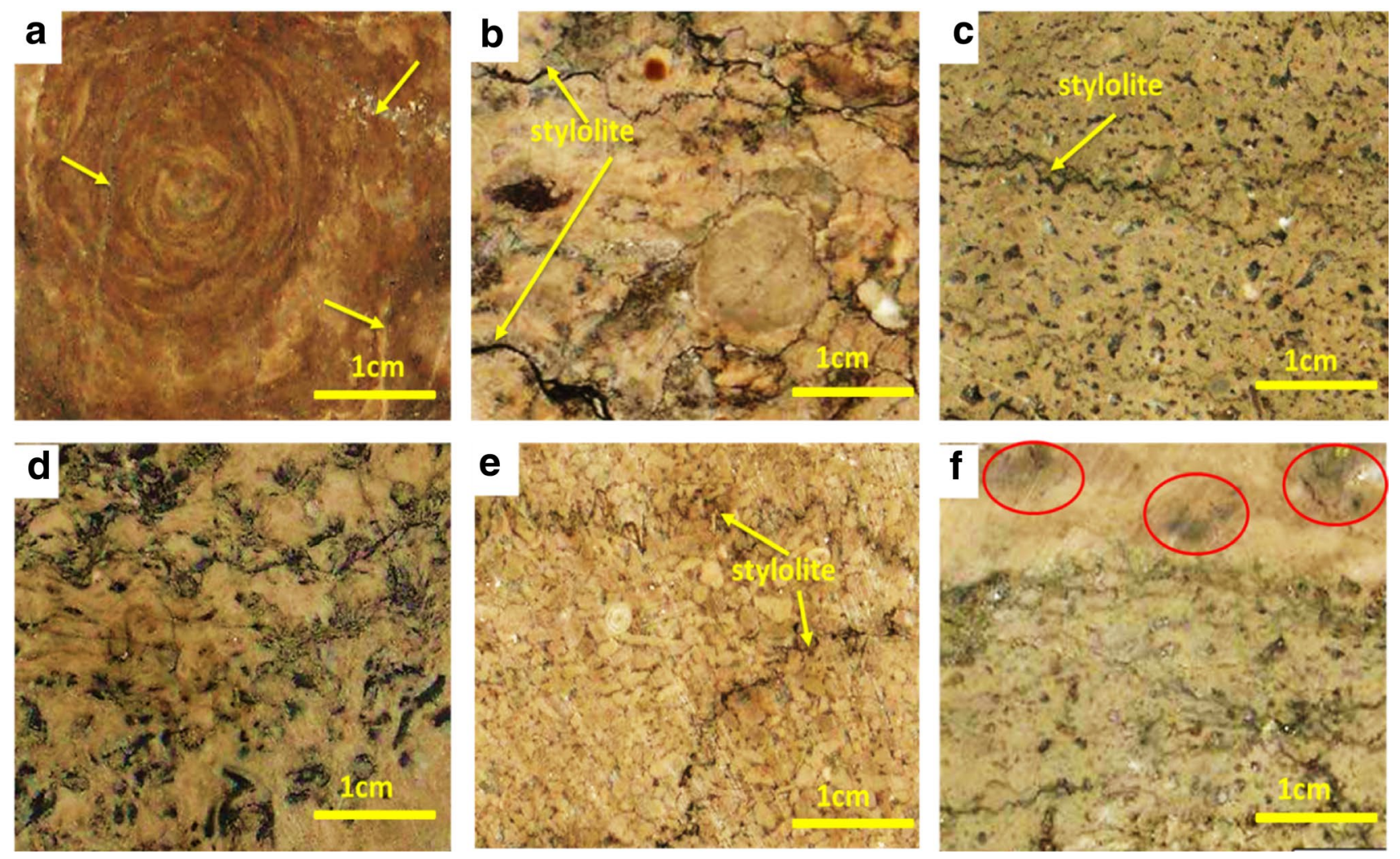

Fig. 5 Core photographs of the reef and shoal facies showing: a argillaceous algae oncoid packstone, with nodules of algae oncoids consisting of alternating light algal calcarenite and reddish brown, tight argillaceous-micritic layers. Fracture filled with sparry calcite (yellow arrows) (MF-1); b intraclasts, bioclastic nodular packstone (MF-9, MF-15), large fragments of corals, bryozoan, with the nodules separated by low- to medium-amplitude stylolites; c intraclasts, bioclastic packstone (MF-9), composed of sand-gravel-sized angular bioclastic disbris and lithoclasts; $\mathbf{d}$ ostracods, coral, oyster wacke- stone-packstone (MF-13) characterized by abundant growth of laminoid fenestrae and wavy hemispheroid laminae; e bioclastic ooidalpeloidal grainstone (MF-10), abundant lithoclasts and sand-sized fossil debris, horizontal and vertical medium-amplitude stylolites (yellow arrows) indicating pressure dissolution and tectonic stress; $\mathbf{f}$ intraclastic algal-coral framestone, small fragments of algae, corals, sponges, echinoids, molluscs shells (MF-16), overlain by coral-algal nodular packstone (red circles) on a marked erosion surface

sand shoals and open platform) and platform margin (reef and sand shoals) during the Lower Ordovician times (Lin et al. 2012; Gao and Fan 2015). On the basis of well logging, cores and thin-section analysis, in addition to depositional characteristics of allochems and early diagenetic features, seventeen microfacies (MF-1 to MF-17) were recognized in the study area. The attributes of these microfacies are shown in Figs. 4, 5, 6 and 7, and the detailed description and interpretation of each type of microfacies are shown in Table 1 . The recognized microfacies are somewhat compared with the Standard Microfacies Types (SMF) of Wilson (1975) and Facies Zones (FZ) of Flügel (2004), and their depositional environments are interpreted following Flügel (2004).

\section{Microfacies characteristics and interpretation}

Deposition in the central Tarim basin especially in the Tazhong Uplift is interpreted to have been on platform interior (restricted subtidal-intertidal platform, intraplatform 

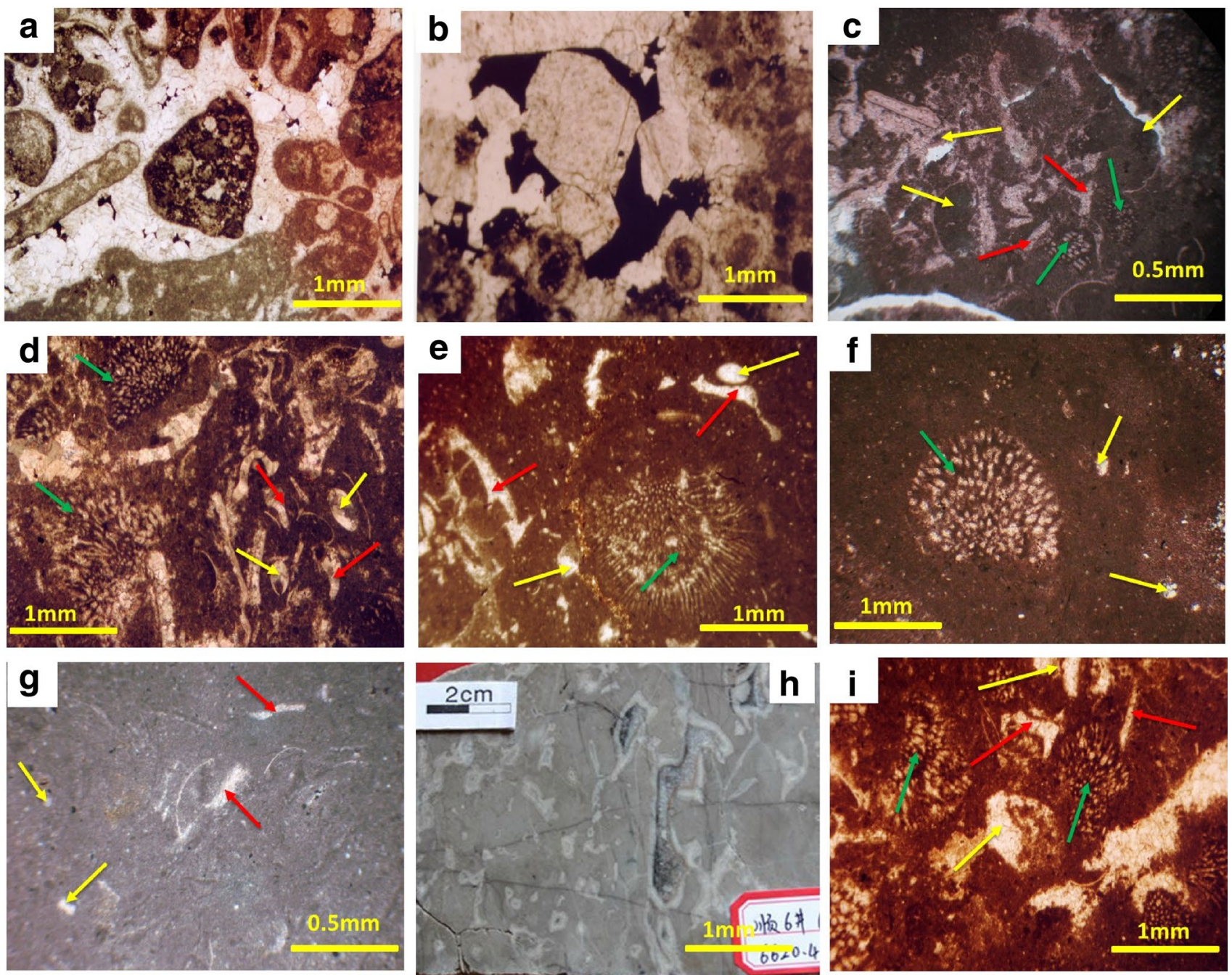

Fig. 6 Photomicrographs of platform reef and shoal microfacies attributes: a bioclastic oncoid packstone (MF-1), under plane polarized light (PPL); b argillaceous bioclastic oncoid packstone (MF-1), under PPL; $\mathbf{c}$ photomicrograph of ooidal grainstone, dissolved vuggy pores empty, under PPL; d algae packstone-grainstone: ostracods (yellow arrows), oysters (red arrows), algae (green arrows), bryozoan (blue arrows) (MF-3), under PPL; e ostracods, oysters, algae floatstone: ostracods (yellow arrows), oysters (red arrow), red cal- careous algae (green arrow) (MF-4), under PPL; f algae mudstonewackestone (MF-6), under PPL; $\mathbf{g}$ oysters lime mudstone (marlstone)/ wackestone: oysters (red arrow), ostracods (yellow arrows) (MF-7), under PPL; $\mathbf{h}$ dolomitic limestone showing dissolved pores along a fracture and irregular vesicular pores; i algae, ostracod, oyster wackestone-packstone: algae (green arrows), ostracods (yellow arrows), oysters (red arrows) (MF-13), under PPL

\section{Microfacies association and interpretation of sedimentary environment}

The carbonate microfacies in this study are described and differentiated using the classification of Dunham (1962) and Embry and Klovan (1971). Six main types of microfacies association (MFA-1 to MFA-6) are recognized and shown in Fig. 8. These microfacies association enabled the recognition of the major environments of deposition, including platform interior and platform margin. Platform reef and shoal facies dominates the shallowing-upward and coarsening-upward cycles in the HST of SQ1-SQ3 in the $\mathrm{O}_{1} \mathrm{P}$ and $\mathrm{O}_{1-2} \mathrm{Y}$ (Fig. 3a, b).

MFA-1 (Fig. 8a) of the $\mathrm{O}_{1} \mathrm{P}$ includes several microfacies (i.e., MF-1 to MF-7). The occurrence of MF-6 and MF-7 at the bottom of the coarsening-upward third-order depositional sequence (SQ1) represented by MFA-1 indicates deposition in a low-energy subtidal environment after a short transgression phase. Succeeding MF-6 and MF-7 microfacies is MF-5 that was deposited in restricted subtidal-intertidal environments under low- to moderate-energy conditions. MF-1 to MF-4 succeed MF-5 and form the top microfacies which are thought to terminate the growth of 

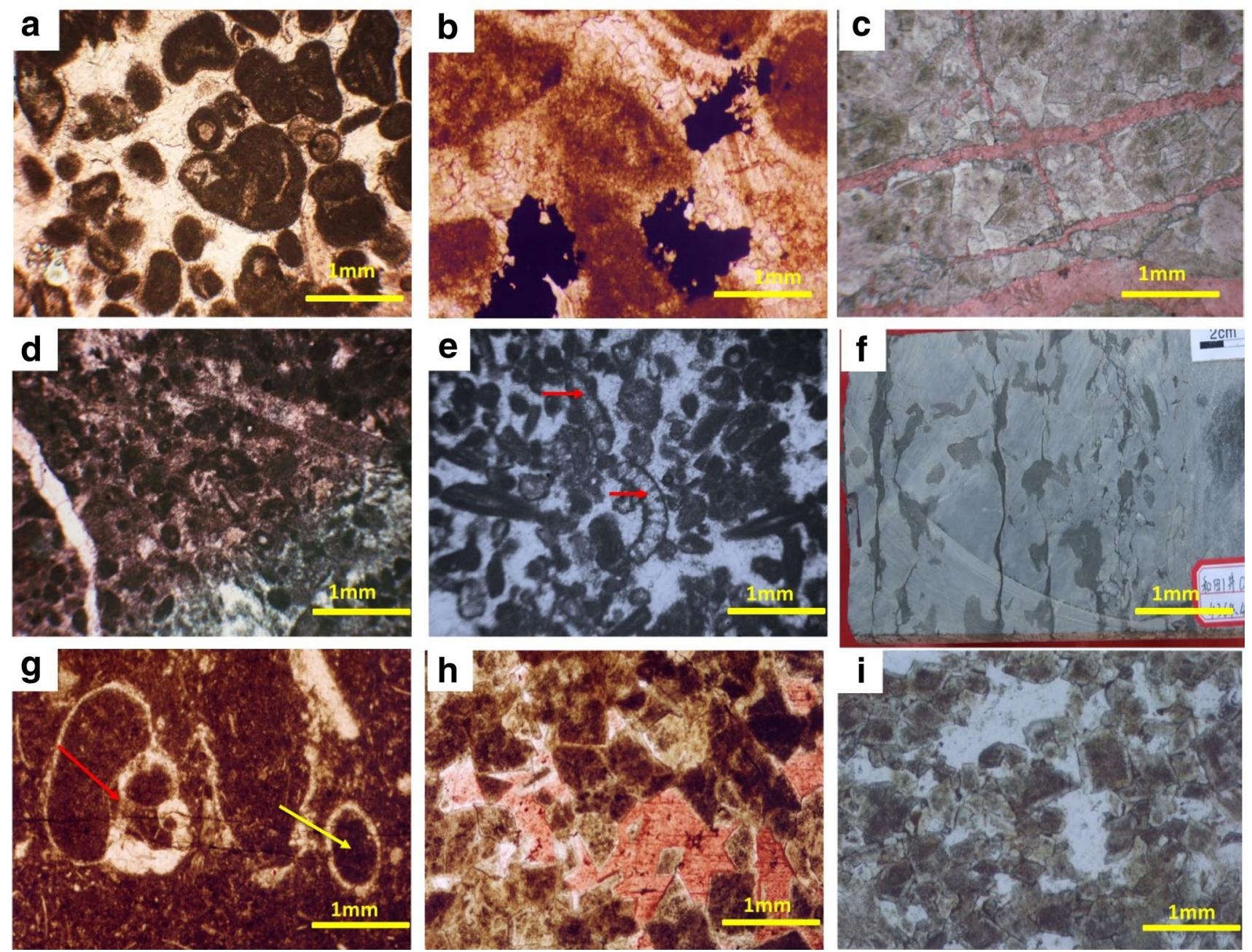

Fig. 7 Photomicrographs of platform reef and shoal microfacies attributes: a bioclastic ooidal-peloidal grainstone (MF-10), under PPL; b ooidal cortoid grainstone: note the large intragranular and grain dissolved vugs isopachous sparry cements and micritic cortices fringing the grains (MF-11), under PPL; c photomicrograph of crystalline dolomite, low- to medium-angle regular horizontal fracture networks, filled with calcite cement, under PPL; $\mathbf{d}$ argillaceous bioclastic peloidal wackestone with micritic intraclasts internal struc- tures resembling bahamite grains (MF-12), under PPL; e bioclastic peloidal grainstone with bryozoan (red arrow) chambers in a long row (MF-14), under PPL; f ooidal-peloidal grainstone, dissolved horizontal microfractures and irregular mottled pores; $\mathrm{g}$ bioclastic wackestone: gastropod (red arrow), ostracod (yellow arrow) (MF-17), under PPL; $\mathbf{h}-\mathbf{i}$ crystalline dolomites with subhedral-euhedral, interfingering rhomb-shaped crystals, showing cloudy cores and bright rims, dissolved vuggy pore filled with calcite cement (MF-5), under PPL reefs as a result of a drop in relative sea level, deposited in restricted supratidal-intertidal zones. Therefore, MFA-1 was developed in the platform interior under low- to moderate-high-energy conditions.

MFA-2 corresponds to the SQ2 and represents the topmost part of the $\mathrm{O}_{1} \mathrm{P}$, comprising many microfacies (Fig. 8b). MF-4, MF-13 MF-14 MF-15 and MF-16 are the microfacies at the bottom of the coarsening-upward cycle of MFA-2 that was probably deposited in shallow restricted environments. MF-10 is the middle microfacies of the cycle and represents reef and sand shoal deposits. MF-8 and MF-9 are the top end microfacies of the cycle that were deposited on platform margin/marginal slopes (i.e., reef slope sand shoals). Based on the above assertions, MFA-2 may have developed in platform interior and platform margin/marginal slopes under low- to moderate-high-energy conditions. The gamma-ray curves associated with MFA-1 and MFA-2 of the SQ1 and SQ2, respectively, in the $\mathrm{O}_{1} \mathrm{P}$ are funnelshaped, having gamma-ray readings ranging from 10 to 75 API units (Fig. 8a, b). The jagged edges of the gamma-ray $\log$ in this figure correspond to mud-rich components in the individual microfacies of the associations. MFA-3 (Fig. 8c) is composed of microfacies that are not very different from those of MFA-1 and MFA-2 and it corresponds to the SQ1 in the $\mathrm{O}_{1-2} \mathrm{Y}$. The occurrence of MF-5 and MF-12 at the base of MFA-3 represents restricted subtidal-intertidal and

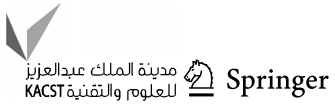




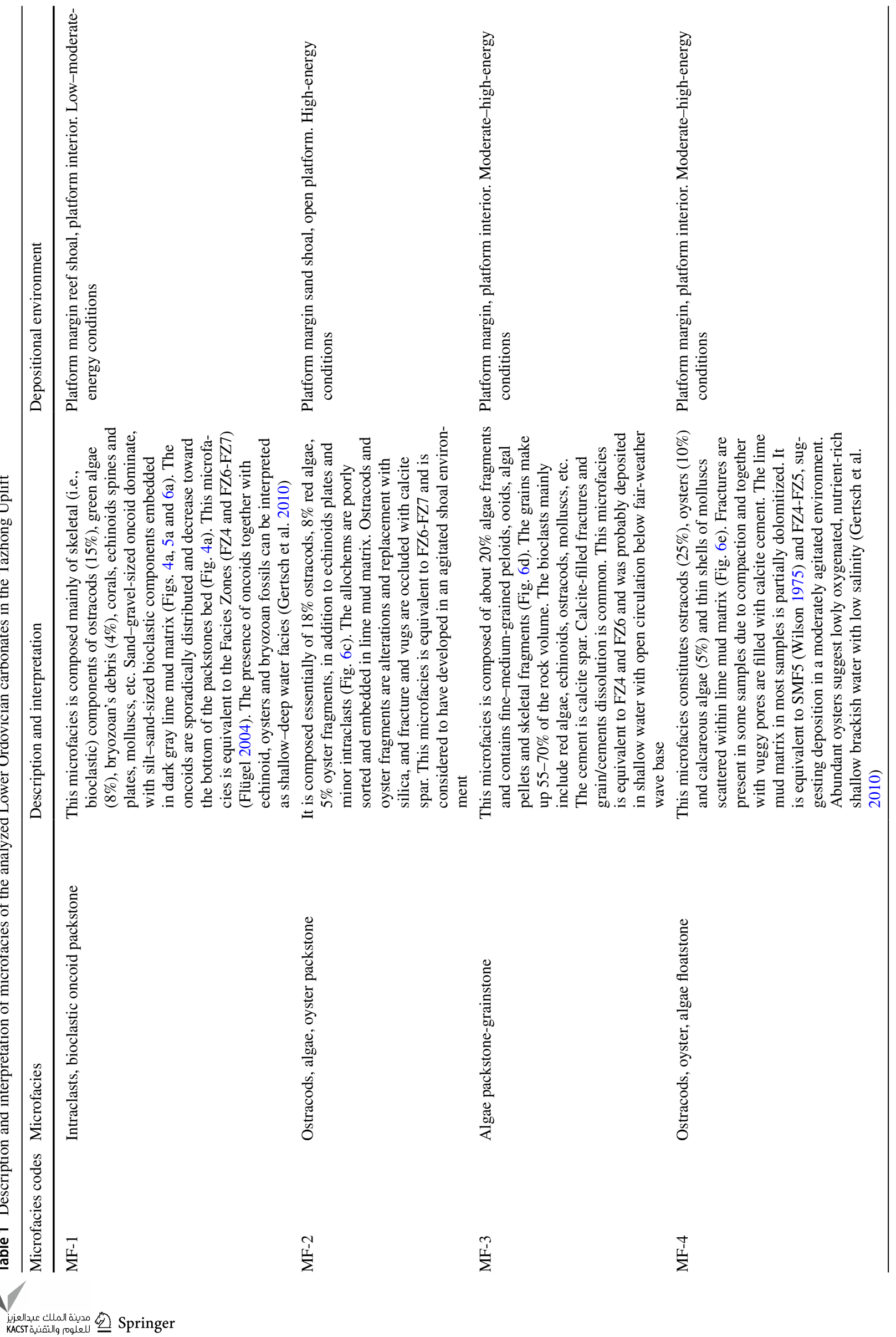




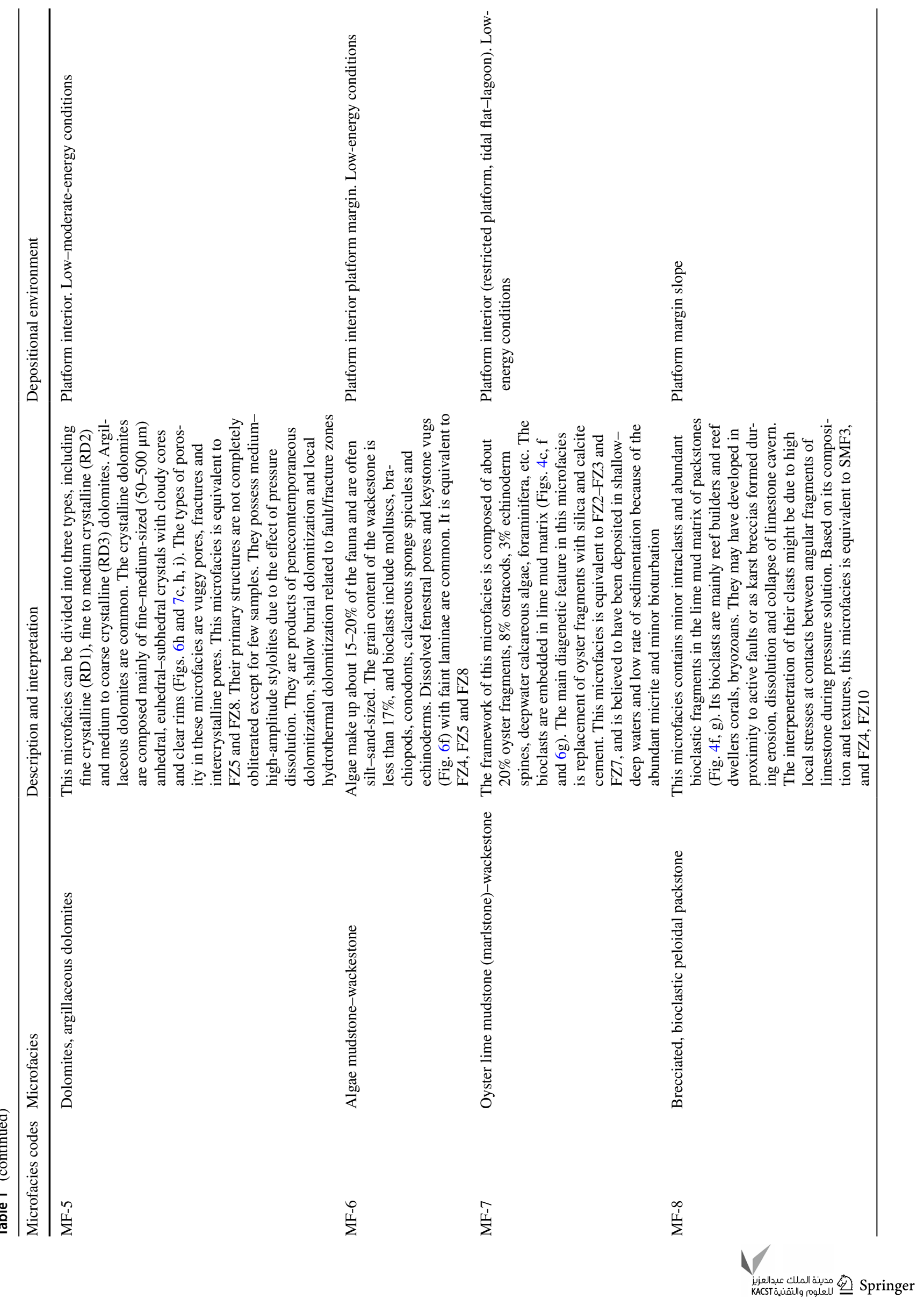




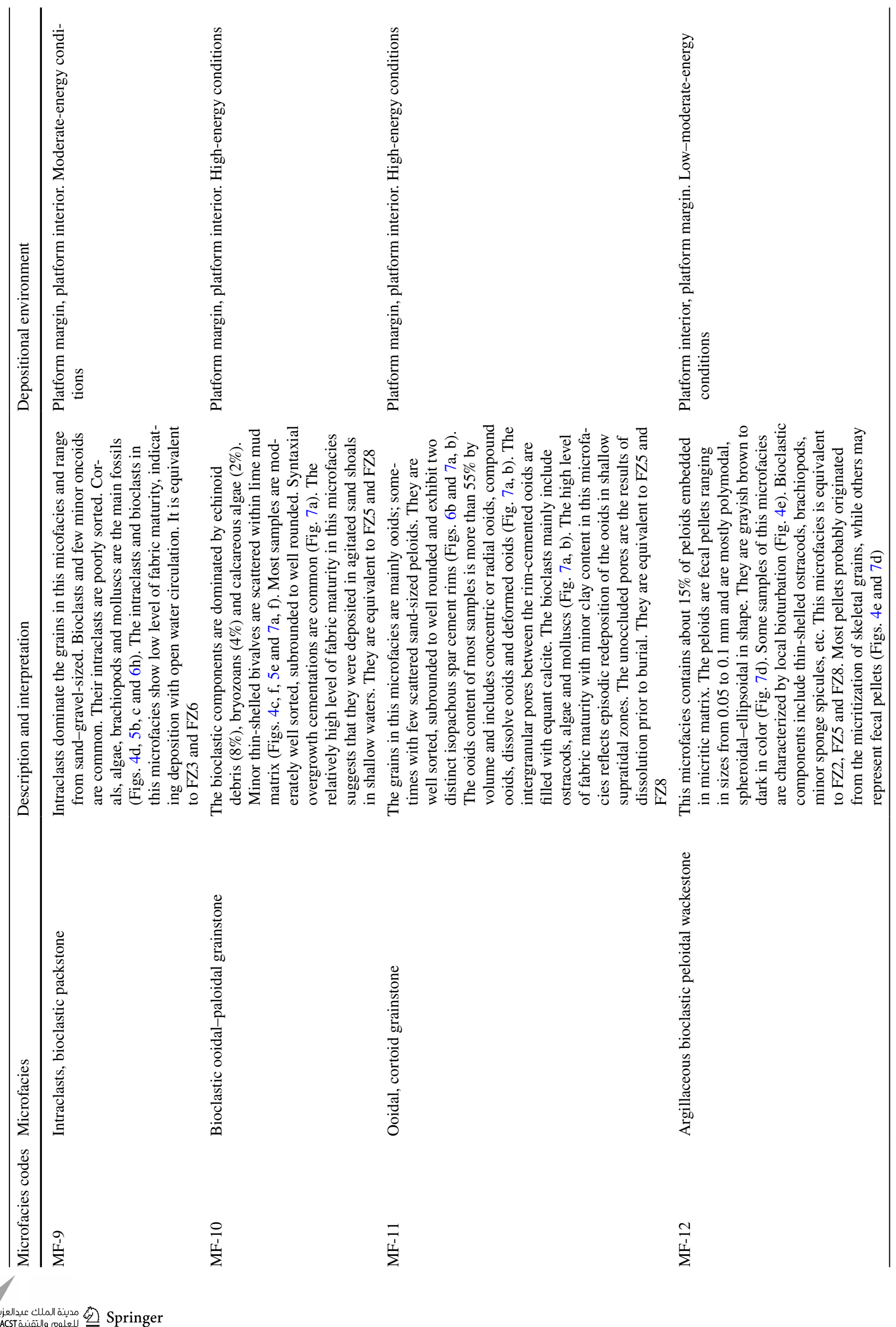




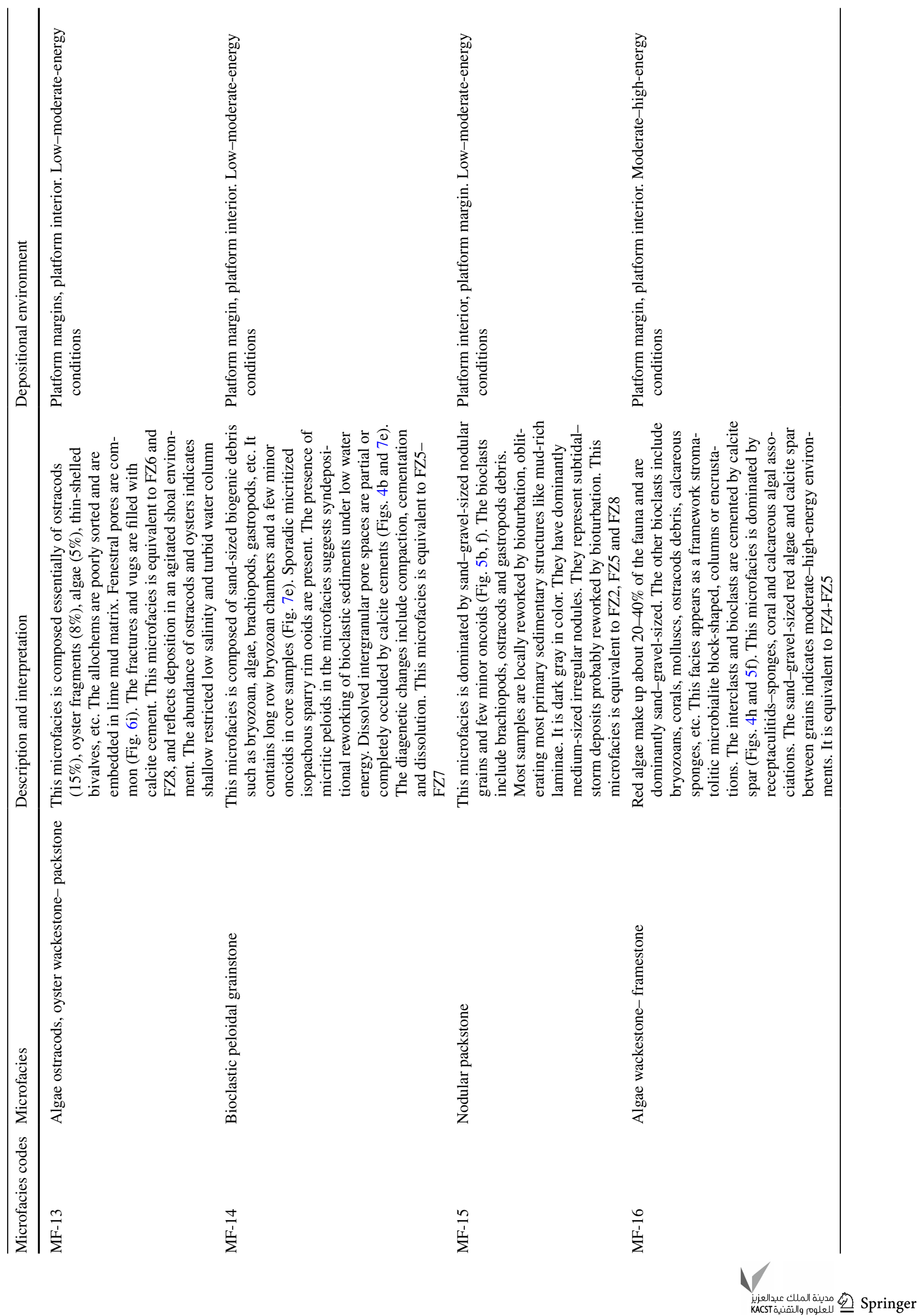




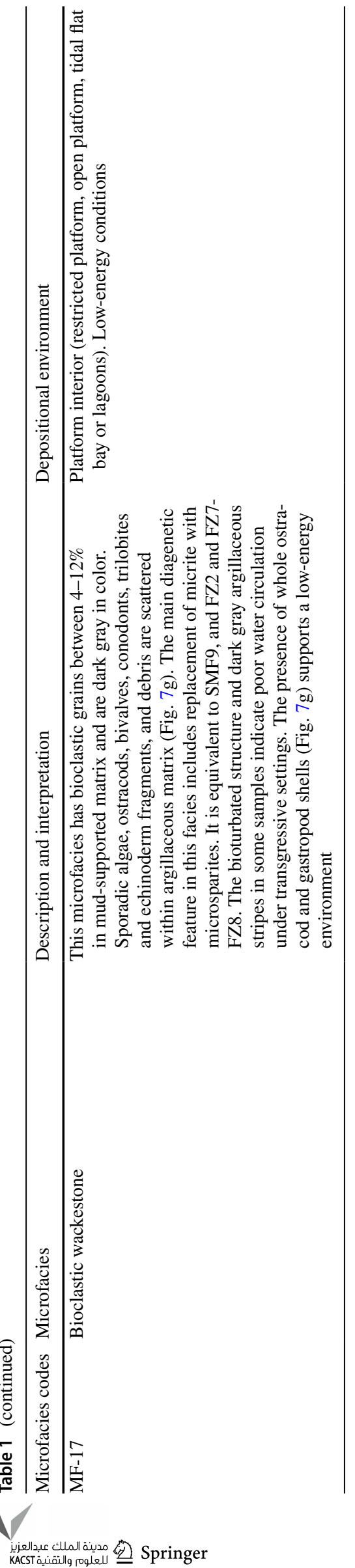

shallow shelf margin deposits. They are related to environment characterized by short period of marine transgression. The microfacies in the middle and top (MF-1, MF-10 and MF-11) of MFA-3 correspond to the HST of SQ1 that may have developed under moderate-high-energy conditions due to a drop in relative sea level. MFA-3 may have developed mainly in the platform interior (e.g., restricted subtidal-intertidal platform, open platform and intraplatform sand shoals).

MFA-4 (Fig. 8d) corresponds to the SQ2 in the $\mathrm{O}_{1-2}$ Y. It has microfacies such as MF-13, MF-15 and MF-16 in the lower part of the coarsening-upward sequence cycle and represents facies deposited under low-moderate-energy conditions. The occurrence of MF-2, MF- 3 and MF-14 in the middle and MF-8, MF-9 and MF-10 at the top of the HST of SQ2 indicates deposition under moderate-highenergy conditions. MFA-4 sequence cycles are common in wells Tz1, Tz2, Tz3, Z2 and Z4 (Figs. 2 and 9), and were developed in platform interior and platform margin under low- to moderate-high-energy conditions. The vertical stacking patterns of the microfacies in MFA-3 and MFA-4 reflect changes in depositional conditions from low-moderate energy at the lower-moderate- and moderate-highenergy conditions at the top of the sequence, respectively.

MFA-5 (Fig. 8e) corresponds to the SQ3 in the middle of the $\mathrm{O}_{1-2} \mathrm{Y}$. MFA- 5 comprises microfacies such as MF-8, MF-9, MF-10, MF-11 and MF-17. The bottom of this microfacies association corresponds to a short period of marine transgression and is represented by MF-17. The middle cycle microfacies correspond to the HST of SQ3 and have microfacies such as MF-10 and MF-11. The faintly laminated structures in most samples of MF-17 and fenestral structures in MF-11 (Fig. 8d, f) are typical of tidal flat-lagoon and restricted shallow marine low-energy environments. MF-8 and MF-9 are the microfacies at the topmost part of MFA-5 and may have developed under moderate-high-energy conditions. Hence, MFA-5 probably developed in platform interior and platform margin/ marginal slopes under low- to moderate-high-energy conditions. The gamma-ray curves of MFA-3, MFA-4 and MFA-5 are funnel-shaped, with wide gamma-ray values ranging from 8 to 90 API units (Fig. $8 \mathrm{c}-\mathrm{e}$ ). The jagged edges of the gamma-ray curves in this figure correspond to argillaceous components in the individual microfacies of the associations. The TST of SQ4 that constitutes the topmost part of the $\mathrm{O}_{1-2} \mathrm{Y}$ corresponds to MFA-6 (Fig. 8f). It comprises microfacies such as MF-11, MF-12, MF-13, MF-14 and MF-17. MF-17 forms the base of MFA-6 and was deposited in a low-energy deep marine environment. MF-13 and MF-14 are coarse-grained microfacies and form the middle cycle of the SQ4 which may have developed under moderate-energy condition. MF-12 interbedded with MF-11 form the topmost microfacies that were 

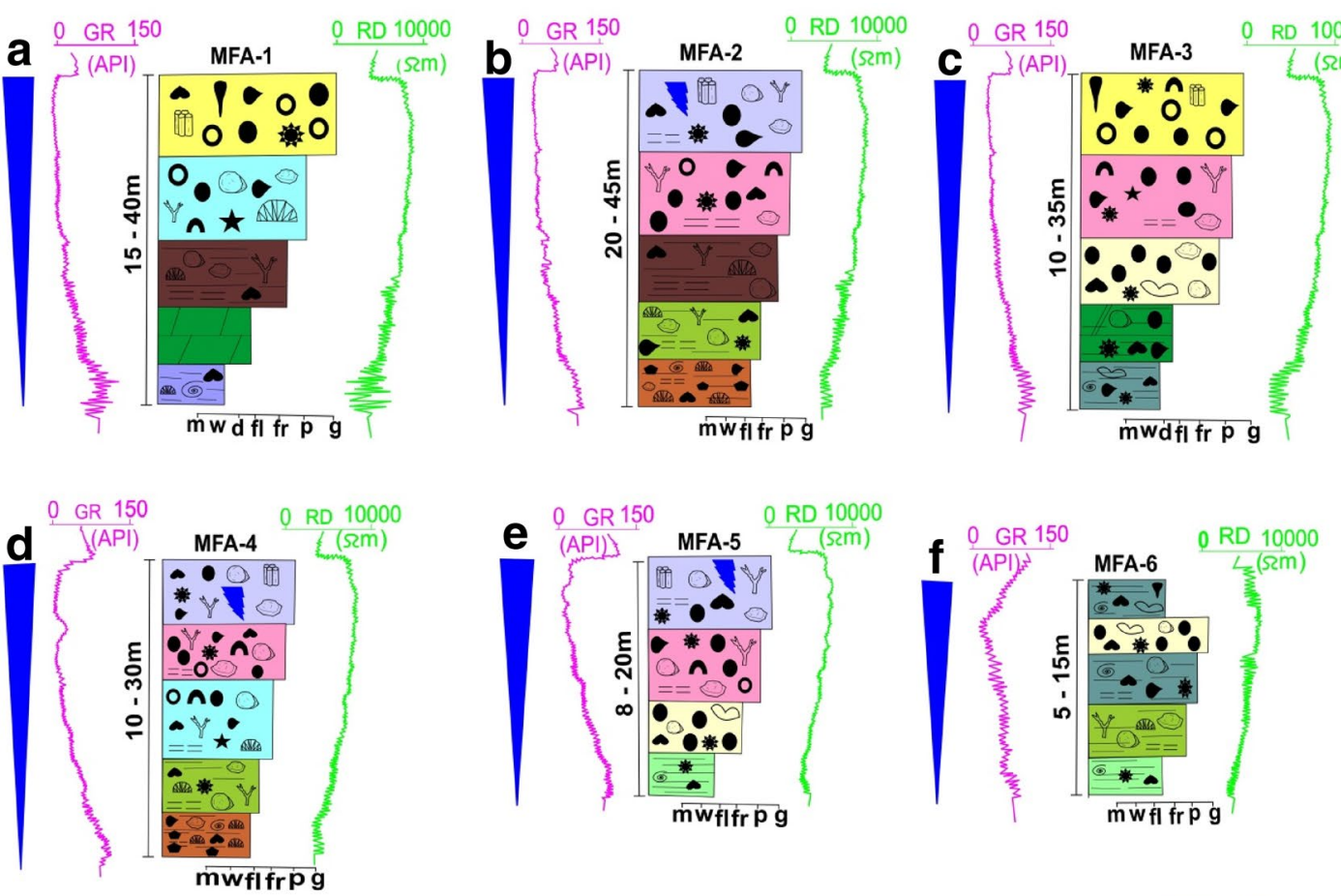

Algae

陮 Coral

Y) Bryozoans

Brachiopods

(20) Ostracods

Echinoids

- Peloids

Ooids

- Oncoids

$=$ Lime mud

Karst hole

(2) Trilobites

(2) Gastropods

Conodonts

// Dolomites

A. Sponges

Fenestral structures

Burrows

Nodules

m Lime mudstone (marl)

W Wackstone

d Dolomites

fl Floatstone

fr Framestone

p Packstone

g Grainstone

MF Microfacies

MFA Microfacies

MF-1 MF-2,3 MF-4 MF-5 MF-6,7 MF-8,9 MF-10 MF-11 MF-12 MF-13,14 MF-15,16 MF-17 Coarsening

upward

Fig. 8 Microfacies associations that developed in platform interior (restricted platform, intraplatform and open platform) and platform margin in the Lower Ordovician carbonate succession. These microfacies associations represent different facies transition trends and third-order sequences

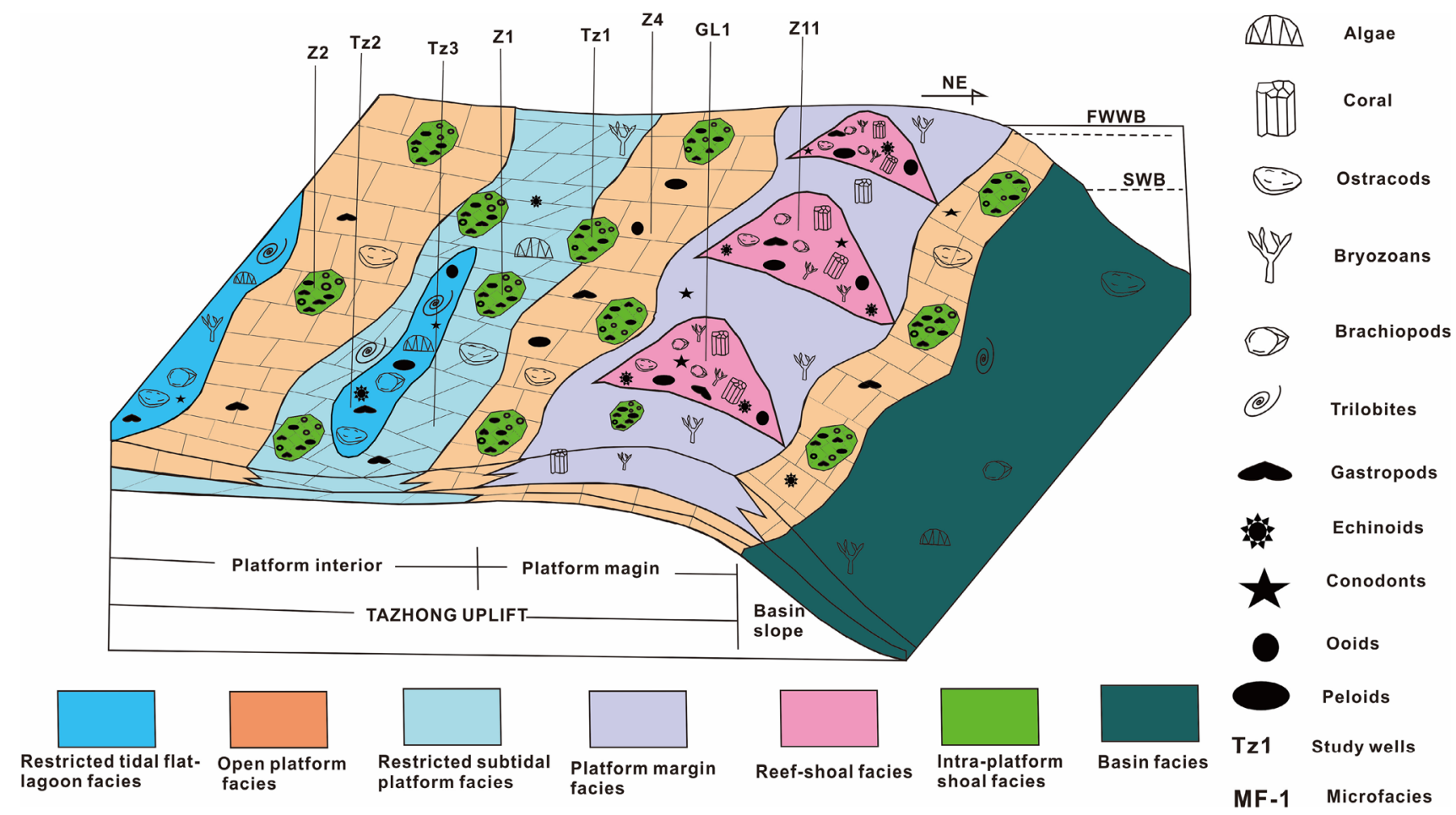

Fig. 9 Depositional model of the coarsening-upward Lower Ordovician carbonate successions in the Tazhong Uplift showing facies distribution within the carbonate platforms and positions of the study wells ( Modified from Gao et al. 2014) 
formed in restricted shallow marine environment. MFA-6 belongs to the Dapingian Stage of the Middle Ordovician and represents a drowning-upward third-order sequence (SQ4) of the carbonate platform that corresponds to a long period of marine transgression (TST) (Yang et al. 2010; Gao and Tailiang 2015). They were deposited in subtidal-tidal flats/lagoon under low-moderate hydrodynamic energy as shown by the increase in mud content toward the top of the SQ4 sequence. The gamma-ray curve for MFA-6 is almost box-shaped with wide gamma-ray values ranging from 6 to 115 API units. Its jagged edges correspond to the argillaceous-rich components of the individual microfacies of the association (Fig. 8f).

\section{Depositional model of the Lower Ordovician carbonate platform in the Tazhong Uplift}

Figure 9 shows a conceptual model which summaries the distribution of the facies on the carbonate platform in the Tazhong Uplift during the Lower Ordovician period. This conceptual model provides a somewhat reference for the interpretation of facies changes in the study area and is proposed based on the variation of microfacies and their corresponding associations. This depositional model should be seen as a predictive tool for this study and not as a detailed paleogeographic reconstruction of the study area.

The area covered by platform facies expanded during the Lower Ordovician, with widespread platform facies in the west of central Tarim basin which later evolved to open platform and restricted platform across a large area, and have many intraplatform shoals (Figs. 2 and 9). The platform reef and shoals' deposits formed during the Lower Ordovician period in the central Tarim basin were mostly aggradational depositional cycles on rimmed carbonate platform (Gao and Fan 2015; Zhu et al. 2017).

During the HST of the SQ1 and SQ2 in the $\mathrm{O}_{1} \mathrm{P}$ (Fig. 3a, b), high-energy reef and shoal facies formed a buffer zone at the platform margin (wells Z11 and GL1) (Figs. 2 and 9) (e.g., Gao and Fan 2015). Open platform facies (well Z4), intraplatform sand shoal facies (wells Z1, Z2 and Tz1) and restricted subtidal-intertidal platform and/or tidal flat-lagoon facies (wells Tz2 and Tz3) constitute the platform interior (Fig. 9). Carbonate sand shoal facies were laterally widespread and prominent in the study area during the Lower Ordovician with vertical stacking pattern cycles that alternately generated thick reefal facies. Sand shoal facies were mainly developed along platform margin/marginal slope breaks, whereas intraplatform sand shoals were developed within the platforms. The platform sand shoal facies were widespread toward the northwestern part of the carbonate platform. Thick reefal and shoal facies are well preserved in cores of wells Z11 and GL1 drilled toward the southeast of the platform. The reef and sand shoals on the platform margin appeared vertically stacked and seem to have developed continuously as an aggradational depositional sequence, while the intraplatform sand shoals within the platforms occurred isolated (Gao and Fan 2015).

Well logging data show that the middle cycle microfacies and topmost cycle microfacies in the HST of SQ1 and SQ2 of the $\mathrm{O}_{1} \mathrm{P}$ which constitutes MFA-1 and MFA-2, respectively, probably terminated the growth of reef and shoals toward the northwestern part of the platform as a result of a drop in relative sea level. The middle and upper cycle microfacies were deposited on open platform (Z4), reef and shoals on platform margin (Z11 and GL1) and intraplatform sand shoals (Tz1, Z1 and Z2) (Figs. 2 and 9), under moderate- to high-energy conditions. The lower cycle microfacies were deposited in low-energy tidal flats (subtidal-supratidal platform) and lagoons (Tz2 and Tz3), and open platform (Z4) (Fig. 9) after a short shallow marine transgressive phase in the platform interior.

The depositional environment of the SQ1-SQ4 in the $\mathrm{O}_{1-2} \mathrm{Y}$ changes frequently from TST to HST (Fig. 3a-c). The microfacies associations (MFA-3 to MFA-6; Fig. 8c-f) represent the lower to upper cycle microfacies of the thirdorder sequences (SQ1-SQ4) in the $\mathrm{O}_{1-2} \mathrm{Y}$. The lower cycle microfacies of MFA-3 to MFA-6 were deposition in the platform interior (Tz2 and Tz3) and on platform margin (Z11) (Fig. 9), characterized by a short period of marine transgression and constituted the TST of the SQ1-SQ4. The middleupper cycle microfacies of MFA-3 to MFA-5 (Fig. 8c-e) constitute the HST of SQ1-SQ3 in the $\mathrm{O}_{1-2} \mathrm{Y}$ and are common in cores from wells drilled in platform interior and reef shoals on platform margin. MFA-6 represents the TST of SQ4 (Fig. 8f) and its microfacies are common in cores from wells drilled in platform interior and platform margin in the study area. The above interpretation suggests that the microfacies of the SQ1-SQ4 in the $\mathrm{O}_{1-2} \mathrm{Y}$ were somewhat not uniformly distributed and show significant distinction in their microfacies from the TST to HST sequence cycles (Fig. 3a, b).

\section{Discussion}

\section{Effects of relative sea-level fluctuation on the depositional sequence cycles}

Meter-scale depositional cycles dominate the shallow marine subtidal-intertidal carbonate successions in the study area and correspond to high-frequency depositional cycles, which are fundamental sequence stratigraphic units of carbonate platforms and basic elements in the interpretation of transgressive-regressive processes (Flügel 2004). The development of a series of microuplifts linked by intraplatform lows and microslopes in the study area could lead to the 
differentiation of sedimentary environments and provide the sedimentary framework of alternating reefs, sand shoals and swamps (Eugene et al. 2006; Gao and Fan 2013; Chen et al. 2018). Widespread platform margin reefs and shoals on microuplifts, and fine-grained facies in low areas between shoals developed during the Lower Ordovician period in the Tazhong Uplift (Gao and Fan 2014a; Zhu et al. 2017) (Figs. 2 and 9). The platform reef and sand shoal facies in this uplift are mostly intraclasts, bioclastic carbonate sandto gravel-sized deposits composed of coarse-grained microfacies such as MF-1, MF-2, MF-3, MF-4, MF-8, MF-9, MF-10, MF-11, MF-13, MF-14 and MF-15, and constitute the coarsening-upward and shallowing-upward cycles of the HST of SQ1-SQ3 in the $\mathrm{O}_{1} \mathrm{P}$ and $\mathrm{O}_{1-2} \mathrm{Y}$. The silt- to finegrained low area (inter-shoals) mircofacies include MF-5, MF-6, MF-7, MF-12, MF-16 and MF-17 that constitutes the deepening-upward and fining-upward cycles of the TST of SQ1-SQ2 in the $\mathrm{O}_{1} \mathrm{P}$ and SQ1-SQ4 in the $\mathrm{O}_{1-2} \mathrm{Y}$.

Regional tectonic movements and relative sea-level changes (frequent transgression-regression transitions) affect the depositional thickness and scale of reefs and shoals of the Lower Ordovician carbonate platform in the Tazhong area. The development of reef and shoal platform in this area corresponds to high-frequency cycles, and early and late period of a falling hemicycle (e.g., Gao et al. 2005; Gao and Tailiang 2015; Chen et al. 2018). As such, highfrequency sea-level fluctuations on carbonate platform presumably manifested as swift transgression and slow regression with multicyclic and high-frequency oscillations (Tan et al. 2009). In addition, each high-frequency sea-level oscillation and rapid transgression generated a low-energy environment with weak hydrodynamic conditions below the fair-weather wave base that resulted in the deposition of deepening-upward and fining-upward sequence cycles dominated by silt- to fine-grained inter-shoal mircofacies (Fig. 3a-c). Subsequently, during early regression or the early phase of sea-level decline and due to vertical stacking pattern sedimentation, underwater microuplift areas were subjected to strong moderate-high-energy conditions above the fair-weather wave base. This resulted in the progressive development of sand-gravel-sized intraclasts, bioclastic sediments on reef and shoal of platform margin. Consequently, the platform sand shoals' sediments gradually grew upward until they reached sea level, resulting in coarsening-upward and shallowing-upward sequence cycles as shown in the HST of SQ1-SQ3 in the $\mathrm{O}_{1} \mathrm{P}$ and $\mathrm{O}_{1-2} \mathrm{Y}$ (Figs. 3a, b and $8 \mathrm{a}-\mathrm{e})$. Under continuous high-frequency relative sea-level fluctuations, multicyclic superimpositions of the vertical stacking patterns or vertical accretion sedimentation are generated on the individual platforms, resulting in multicyclic development of reef and sand shoal microfacies (Fig. 3a-c). On carbonate platforms with paleomicro-uplifts linked by intraplatform lows and microslopes, high-frequency relative sea-level variations associated with rapid transgressive phase and slow regression presumably favored the deposition of large-scale shallowing-upward and coarsening-upward vertical stacking patterns of meter-scale cycles (SQ1-SQ3) of reef and shoal facies. These large-scale facies stacking patterns probably developed in response to abundant growth of biogenic sediments under moderate-high hydrodynamic conditions that repeatedly rework and distributed the bioclastic debris across the platforms. These facies stacking patterns corresponds to high-frequency depositional cycles enhanced by the direction and strength of wave and tidal currents, which, in turn, controls the scale of the multicyclic vertical stacking patterns of the platform reef and shoal during relative sea-level drop (Sfidari et al. 2014; Gao and Tailiang 2015).

In summary, relatively low paleomicro-uplifts on carbonate platforms, tectonics and frequent relative sea-level fluctuation associated with swift transgressive phase and slow regression are the main factors influencing the development of the large-scale high-frequency reef and shoal facies stacking patterns across the carbonate platforms in the Tazhong Uplift.

\section{The evolutionary patterns, characteristics and types of hydrocarbon reservoirs in reef and shoal complexes in the Tazhong area}

\section{The evolutionary patterns of hydrocarbon reservoirs in reef and shoal complexes}

The multiphase episodes of intense tectonic activity in the Tazhong Uplift during the Caledonian and early-late Hercynian orogeny (Wu et al. 2012) could have exerted substantial influence on the deeply buried Lower Paleozoic carbonate rocks as they were penetrated by the intrusive diabases and volcanic eruptive edifice through geothermal/hydrothermal fluid inputs (Chen et al. 1997; Jiang et al. 2015; Guo et al. 2016; Ngia et al. 2019). As a result, conjugate fault systems and related fracture networks were created in the Cambrian to Lower Ordovician sedimentary packages particularly in the Tazhong area (Wu et al. 2012; Li et al. 2013a, b).

High-temperature oil field gases $\left(\mathrm{CO}_{2}, \mathrm{HF}\right.$ and $\left.\mathrm{H}_{2} \mathrm{~S}\right)$ generated from relatively deep strata from hydrothermal decomposition of hydrocarbon (e.g., Li et al. 2014; Cai et al. 2014, 2015a, 2016; Jiang et al. 2015) diluted with Mg-rich saline formation waters forms the geothermal/ hydrothermal fluids (Cai et al. 2008, 2009b; Yang et al. 2012; Jiang et al. 2015; Li and Cai 2017; Ngia et al. 2019). This thermochemical sulfate reduction derived hightemperature basinal dissolution fluids driven by convective-advective flow, migrate upward along structures like faults and related fracture networks, permeable horizons

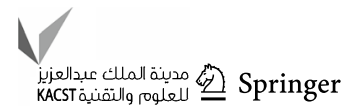


and brecciation that act as conduits for the upward and lateral migration from depth. As such, high-quality carbonate reservoirs are better developed along the faults and related fracture networks and permeable horizons that act as migration pathways for these hot active basinal fluids (TSR and geothermal/hydrothermal). However, the premise for fluid lateral migration is that the rocks with original relatively high primary porosity and permeability (i.e., macroscopic intercrystalline and intracrystalline pores in dolomites, bioclastic ooidal to peloidal packstone grainstones, intraclasts bioclastic oncoid packstone, brecciated bioclastic peloidal packstone, intraclasts bioclastic packstone, ooidal, cortoid grainstone, bioclastic peloidal grainstone, etc.) in high-energy reef shoal facies of the $\mathrm{O}_{1} \mathrm{P}$ and $\mathrm{O}_{1-2} \mathrm{Y}$ are the facies where secondary vuggy/ moldic porosity would further develop during the shallow to deep burial diagenetic process. This interpretation is supported by the preferential occurrence of large secondary pore spaces, including dissolved vuggy/moldic pores, intercrystalline pores, solution-enlarged fractures, etc., with varying sizes (up to several centimeters in size and $12 \%$ porosity) in the carbonate microfacies in the study Lower Ordovician strata, which are somewhat close to the faults and related fractures.

Moreover, mesogenetic dissolution (shallow burial) has been proposed as a viable means of carbonates and sulfates dissolution, and thus significantly improved or rearranged the previous porosity (e.g., Mazzullo and Harris 1992; Li et al. 2014; Cai et al. 2014; Jiang et al. 2015). The mesogenetic fluids (carbonic acid, sulfuric acid, $\mathrm{H}_{2} \mathrm{~S}$, HF and organic acids) associated with kerogen maturation and early petroleum charge from deeply buried Cambrian source rocks (Jin et al. 2009; Cai et al. 2002, 2009a, b, 2015b, 2016) are formed during hydrocarbon generation. The mesogenetic dissolution fluids, geothermal/hydrothermal basinal fluids and TSR-related fluids (e.g., Mazzullo and Harris 1992; Worden and Smalley 1996; Cai et al. 2001, 2003, 2004, 2008, 2015a, b, 2016; Jin et al. 2009; Yang et al. 2012; Li et al. 2014; Jiang et al. 2015; Jia et al. 2015, 2016; Li and Cai 2017) generated at depth are responsible for the development of volumetrically significant macroscopic intercrystalline, vuggy/moldic and dissolved fracture porosity in most carbonate microfacies in the Lower Ordovician strata in the study area. Although secondary hydrocarbon reservoir spaces generated by mesogenetic dissolution fluids, geothermal/hydrothermal basinal fluids and TSR-related fluids mimic with those created by meteoric dissolution fluids, the secondary pore spaces generated by the former are relatively larger, deeply penetrating and possess relatively good reservoir qualities, thereby contributing significantly to the development of hydrocarbon reservoir spaces in shallow burial carbonates in the study area.
The petrophysical properties, characteristics and types of hydrocarbon reservoir in reef and shoal complexes in the Tazhong area

Carbonate platform reef and shoal complex are the main targets of hydrocarbon exploration in the Lower Paleozoic strata in central Tarim basin (Zhao et al. 2007; Li et al. 2012; Lan et al. 2013; Gao and Fan 2015; Fu et al. 2017). Hydrocarbon reservoirs in reef and shoal facies are widely developed in the Lower Ordovician carbonate platforms in the Tazhong Uplift in central Tarim basin (e.g., Zhao et al. 2007).

\section{Petrophysical properties of the hydrocarbon reservoirs}

Hydrocarbon reservoirs with high porosity and permeability are assembled in the Lower Ordovician high-energy reef and shoal facies in the $\mathrm{O}_{1} \mathrm{P}$ and $\mathrm{O}_{1-2} \mathrm{Y}$. Three hundred and nineteen (350) samples of seventeen reef and shoal microfacies (MF-1 to MF-17) were obtained from eight wells in the carbonate successions of the $\mathrm{O}_{1} \mathrm{P}$ and $\mathrm{O}_{1-2} \mathrm{Y}$ in the Tazhong Uplift and analyzed for their petrophysical properties (Table 2).

The results of the average porosity and permeability of the seventeen microfacies (MF-1 to MF-17) reservoirs in the Penglaiba Formation are: MF-1 $(4.95 \%)$ and $\left(0.428 \times 10^{-3} \mathrm{mD}\right), \mathrm{MF}-2(4.15 \%)$ and $\left(0.425 \times 10^{-3} \mathrm{mD}\right)$, MF-3 (3.44\%) and $\left(0.582 \times 10^{-3} \mathrm{mD}\right), \mathrm{MF}-4(2.03 \%)$ and $\left(0.119 \times 10^{-3} \mathrm{mD}\right), \mathrm{MF}-5(5.97 \%)$ and $\left(1.614 \times 10^{-3} \mathrm{mD}\right)$, MF-6 (1.12\%) and $\left(0.124 \times 10^{-3} \mathrm{mD}\right)$, MF-7 (5.97\%) and $\left(0.697 \times 10^{-3} \mathrm{mD}\right)$, MF-8 $(3.56 \%)$ and $\left(0.769 \times 10^{-3} \mathrm{mD}\right)$, MF-9 $(1.69 \%)$ and $\left(0.427 \times 10^{-3} \mathrm{mD}\right)$, MF-10 $(5.86 \%)$ and $\left(0.689 \times 10^{-3} \mathrm{mD}\right), \mathrm{MF}-11(5.72 \%)$ and $\left(0.489 \times 10^{-3} \mathrm{mD}\right)$, MF-12 (1.28\%) and $\left(0.489 \times 10^{-3} \mathrm{mD}\right), \mathrm{MF}-13(1.48 \%)$ and $\left(0.175 \times 10^{-3} \mathrm{mD}\right), \mathrm{MF}-14(3.46 \%)$ and $\left(0.560 \times 10^{-3} \mathrm{mD}\right)$, MF-15 (2.03\%) and $\left(0.287 \times 10^{-3} \mathrm{mD}\right), \mathrm{MF}-16(3.74 \%)$ and $\left(0.902 \times 10^{-3} \mathrm{mD}\right)$, and $\mathrm{MF}-17(1.51 \%)$ and $\left(0.306 \times 10^{-3} \mathrm{mD}\right)($ Fig. 10a-h).

On the other hand, the values of the average porosity and permeability of the seventeen microfacies (MF-1 to MF-17) reservoirs in the Yingshan Formation are slightly higher than those of their counterpart in the Penglaiba Formation, and these values are: MF-1 $(3.66 \%)$ and $\left(0.554 \times 10^{-3} \mathrm{mD}\right)$, MF-2 (4.24\%) and $\left(0.527 \times 10^{-3} \mathrm{mD}\right)$, MF-3 (4.26\%) and $\left(0.478 \times 10^{-3} \mathrm{mD}\right)$, MF-4 $(3.02 \%)$ and $\left(0.377 \times 10^{-3} \mathrm{mD}\right)$, MF-5 (2.84\%) and $\left(0.683 \times 10^{-3} \mathrm{mD}\right)$, MF-6 $(1.18 \%)$ and $\left(0.277 \times 10^{-3} \mathrm{mD}\right)$, MF-7 $(1.86 \%)$ and $\left(0.487 \times 10^{-3} \mathrm{mD}\right)$, MF-8 (3.28\%) and $\left(1.128 \times 10^{-3} \mathrm{mD}\right)$, MF-9 (3.52\%) and $\left(0.466 \times 10^{-3} \mathrm{mD}\right), \mathrm{MF}-10(6.53 \%)$ and $\left(1.118 \times 10^{-3} \mathrm{mD}\right)$, MF-11 (4.53\%) and $\left(0.842 \times 10^{-3} \mathrm{mD}\right), \mathrm{MF}-12(1.79 \%)$ and $\left(0.692 \times 10^{-3} \mathrm{mD}\right), \mathrm{MF}-13(2.4 \%)$ and $\left(0.514 \times 10^{-3} \mathrm{mD}\right)$, MF-14 (3.33\%) and $\left(0.757 \times 10^{-3} \mathrm{mD}\right)$, MF-15 (2.39\%) and $\left(0.742 \times 10^{-3} \mathrm{mD}\right), \mathrm{MF}-16(3.79 \%)$ and $\left(0.691 \times 10^{-3} \mathrm{mD}\right)$, 
Table 2 Porosity and permeability data for the analyzed Lower Ordovician carbonate microfacies (MF-1 to MF-17) samples from the Tazhong Uplift in central Tarim basin

\begin{tabular}{|c|c|c|c|c|c|c|c|c|c|}
\hline \multirow[t]{2}{*}{ Formation } & \multirow[t]{2}{*}{ Microfacies } & \multicolumn{3}{|c|}{ Porosity (\%) } & \multirow[t]{2}{*}{ Freq. (\%) } & \multicolumn{3}{|c|}{ Permeability $\left(\times 10^{-3} \mathrm{mD}\right)$} & \multirow[t]{2}{*}{ Freq. $(\%)$} \\
\hline & & Max & Min & Mean & & Max & Min & Mean & \\
\hline \multirow[t]{3}{*}{$\mathrm{O}_{1} \mathrm{P}$} & MF-1 & 6.44 & 1.82 & 5.42 & 5 & 1.412 & 0.003 & 0.462 & 5 \\
\hline & MF-1 & 7.51 & 2.11 & 6.52 & 4 & 2.302 & 0.061 & 0.421 & 4 \\
\hline & MF-1 & 6.44 & 1.75 & 2.94 & 4 & 2.541 & 0.011 & 0.401 & 4 \\
\hline \multirow[t]{2}{*}{$\mathrm{O}_{1-2} \mathrm{Y}$} & MF-1 & 7.13 & 2.21 & 2.67 & 5 & 3.001 & 0.052 & 0.721 & 5 \\
\hline & MF-1 & 4.91 & 1.81 & 2.01 & 6 & 2.211 & 0.012 & 0.387 & 6 \\
\hline \multirow[t]{3}{*}{$\mathrm{O}_{1} \mathrm{P}$} & MF-2 & 5.36 & 2.02 & 4.32 & 4 & 2.112 & 0.013 & 0.381 & 4 \\
\hline & MF-2 & 6.51 & 2.32 & 4.52 & 6 & 2.422 & 0.042 & 0.411 & 6 \\
\hline & MF-2 & 6.74 & 2.18 & 3.61 & 4 & 2.216 & 0.013 & 0.482 & 4 \\
\hline \multirow[t]{2}{*}{$\mathrm{O}_{1-2} \mathrm{Y}$} & MF-2 & 7.34 & 2.12 & 4.52 & 5 & 3.114 & 0.005 & 0.492 & 5 \\
\hline & MF-2 & 8.56 & 1.05 & 3.95 & 3 & 3.321 & 0.015 & 0.561 & 3 \\
\hline \multirow[t]{2}{*}{$\mathrm{O}_{1} \mathrm{P}$} & MF-3 & 8.43 & 1.58 & 4.07 & 5 & 3.312 & 0.054 & 0.742 & 5 \\
\hline & MF-3 & 5.96 & 1.61 & 2.81 & 4 & 2.102 & 0.022 & 0.421 & 4 \\
\hline \multirow[t]{2}{*}{$\mathrm{O}_{1-2} \mathrm{Y}$} & MF-3 & 5.63 & 3.32 & 3.48 & 3 & 2.821 & 1.042 & 0.412 & 3 \\
\hline & MF-3 & 6.81 & 3.70 & 5.03 & 4 & 3.532 & 0.064 & 0.543 & 4 \\
\hline \multirow[t]{2}{*}{$\mathrm{O}_{1} \mathrm{P}$} & MF-4 & 2.74 & 0.72 & 1.74 & 7 & 0.623 & 0.026 & 0.017 & 7 \\
\hline & MF-4 & 2.81 & 1.52 & 2.32 & 4 & 1.043 & 0.017 & 0.221 & 4 \\
\hline \multirow[t]{2}{*}{$\mathrm{O}_{1-2} \mathrm{Y}$} & MF-4 & 3.11 & 1.84 & 2.91 & 6 & 1.214 & 0.007 & 0.322 & 6 \\
\hline & MF-4 & 3.64 & 1.93 & 3.32 & 4 & 0.823 & 0.003 & 0.431 & 4 \\
\hline \multirow[t]{6}{*}{$\mathrm{O}_{1} \mathrm{P}$} & MF-5 & 3.52 & 2.61 & 2.92 & 6 & 1.734 & 0.031 & 1.701 & 6 \\
\hline & MF-5 & 5.63 & 4.32 & 4.42 & 8 & 2.801 & 1.822 & 2.142 & 8 \\
\hline & MF-5 & 6.81 & 5.70 & 6.01 & 9 & 3.512 & 0.084 & 2.431 & 9 \\
\hline & MF-5 & 7.51 & 2.11 & 6.52 & 4 & 2.312 & 0.067 & 0.941 & 4 \\
\hline & MF-5 & 8.21 & 2.31 & 5.34 & 5 & 2.451 & 0.021 & 0.512 & 5 \\
\hline & MF-5 & 9.11 & 3.24 & 4.65 & 3 & 3.112 & 1.212 & 0.341 & 3 \\
\hline \multirow[t]{4}{*}{$\mathrm{O}_{1-2} \mathrm{Y}$} & MF-5 & 0.94 & 0.84 & 0.89 & 2 & 0.017 & 0.012 & 0.015 & 2 \\
\hline & MF-5 & 2.51 & 1.01 & 1.71 & 4 & 1.522 & 0.092 & 1.311 & 4 \\
\hline & MF-5 & 8.02 & 2.32 & 5.21 & 6 & 3.122 & 0.202 & 0.872 & 6 \\
\hline & MF-5 & 6.75 & 2.73 & 3.62 & 3 & 2.102 & 0.036 & 0.534 & 3 \\
\hline \multirow[t]{2}{*}{$\mathrm{O}_{1} \mathrm{P}$} & MF-6 & 2.71 & 0.63 & 1.21 & 3 & 0.533 & 0.024 & 0.027 & 3 \\
\hline & MF-6 & 2.12 & 1.22 & 1.03 & 4 & 0.643 & 0.013 & 0.221 & 4 \\
\hline \multirow[t]{2}{*}{$\mathrm{O}_{1-2} \mathrm{Y}$} & MF-6 & 2.41 & 1.04 & 1.11 & 3 & 0.314 & 0.005 & 0.122 & 3 \\
\hline & MF-6 & 2.14 & 1.33 & 1.24 & 5 & 0.923 & 0.006 & 0.431 & 5 \\
\hline \multirow[t]{2}{*}{$\mathrm{O}_{1} \mathrm{P}$} & MF-7 & 6.44 & 1.82 & 5.42 & 7 & 1.519 & 0.005 & 0.452 & 7 \\
\hline & MF-7 & 7.51 & 2.11 & 6.52 & 8 & 2.312 & 0.067 & 0.941 & 8 \\
\hline $\mathrm{O}_{1-2} \mathrm{Y}$ & MF-7 & 4.72 & 1.35 & 2.54 & 6 & 2.234 & 0.015 & 0.742 & 6 \\
\hline & MF-7 & 2.31 & 1.02 & 1.17 & 3 & 0.673 & 0.024 & 0.231 & 3 \\
\hline $\mathrm{O}_{1} \mathrm{P}$ & MF-8 & 6.54 & 1.62 & 3.42 & 3 & 1.219 & 0.055 & 0.652 & 3 \\
\hline & MF-8 & 7.61 & 2.21 & 4.02 & 3 & 2.012 & 0.107 & 0.943 & 3 \\
\hline & MF-8 & 7.21 & 2.51 & 3.24 & 4 & 2.211 & 0.141 & 0.712 & 4 \\
\hline $\mathrm{O}_{1-2} \mathrm{Y}$ & MF-8 & 8.21 & 3.21 & 3.67 & 3 & 2.102 & 0.212 & 0.841 & 3 \\
\hline & MF-8 & 6.22 & 1.62 & 3.54 & 4 & 1.112 & 0.351 & 0.734 & 4 \\
\hline & MF-8 & 5.12 & 2.23 & 2.62 & 5 & 2.213 & 0.121 & 0.681 & 5 \\
\hline $\mathrm{O}_{1} \mathrm{P}$ & MF-9 & 4.12 & 1.21 & 2.34 & 3 & 1.821 & 0.024 & 0.201 & 3 \\
\hline & MF-9 & 5.76 & 1.62 & 2.05 & 3 & 2.102 & 0.214 & 0.432 & 3 \\
\hline $\mathrm{O}_{1-2} \mathrm{Y}$ & MF-9 & 7.81 & 1.64 & 5.34 & 5 & 2.832 & 0.044 & 0.914 & 5 \\
\hline & MF-9 & 2.21 & 0.63 & 1.72 & 6 & 0.963 & 0.002 & 0.018 & 6 \\
\hline $\mathrm{O}_{1} \mathrm{P}$ & MF-10 & 5.21 & 1.55 & 4.63 & 5 & 1.114 & 0.002 & 0.634 & 5 \\
\hline & MF-10 & 7.46 & 1.62 & 6.31 & 9 & 2.144 & 0.008 & 0.403 & 9 \\
\hline & MF-10 & 8.23 & 1.74 & 6.63 & 6 & 2.523 & 0.024 & 1.032 & 6 \\
\hline
\end{tabular}


Table 2 (continued)

\begin{tabular}{|c|c|c|c|c|c|c|c|c|c|}
\hline \multirow[t]{2}{*}{ Formation } & \multirow[t]{2}{*}{ Microfacies } & \multicolumn{3}{|c|}{ Porosity (\%) } & \multirow[t]{2}{*}{ Freq. $(\%)$} & \multicolumn{3}{|c|}{ Permeability $\left(\times 10^{-3} \mathrm{mD}\right)$} & \multirow[t]{2}{*}{ Freq. (\%) } \\
\hline & & Max & Min & Mean & & Max & Min & Mean & \\
\hline \multirow[t]{2}{*}{$\mathrm{O}_{1-2} \mathrm{Y}$} & MF-10 & 9.62 & 2.42 & 7.72 & 8 & 3.134 & 0.051 & 1.321 & 8 \\
\hline & MF-10 & 7.83 & 1.62 & 5.33 & 5 & 2.822 & 0.054 & 0.814 & 5 \\
\hline \multirow[t]{2}{*}{$\mathrm{O}_{1} \mathrm{P}$} & MF-11 & 6.53 & 1.42 & 5.43 & 7 & 2.022 & 0.064 & 0.601 & 7 \\
\hline & MF-11 & 6.24 & 1.34 & 4.74 & 5 & 1.464 & 0.032 & 0.321 & 5 \\
\hline \multirow[t]{2}{*}{$\mathrm{O}_{1-2} \mathrm{Y}$} & MF-11 & 7.53 & 2.21 & 6.52 & 4 & 2.222 & 0.066 & 0.942 & 4 \\
\hline & MF-11 & 4.72 & 1.35 & 2.54 & 6 & 2.234 & 0.015 & 0.742 & 6 \\
\hline \multirow[t]{2}{*}{$\mathrm{O}_{1} \mathrm{P}$} & MF-12 & 2.72 & 0.61 & 1.34 & 3 & 0.813 & 0.031 & 0.327 & 3 \\
\hline & MF-12 & 2.41 & 1.02 & 1.21 & 5 & 0.647 & 0.022 & 0.323 & 5 \\
\hline \multirow[t]{2}{*}{$\mathrm{O}_{1-2} \mathrm{Y}$} & MF-12 & 3.51 & 1.34 & 1.57 & 4 & 1.104 & 0.013 & 0.532 & 4 \\
\hline & MF-12 & 3.32 & 1.65 & 2.01 & 3 & 1.023 & 0.043 & 0.851 & 3 \\
\hline \multirow[t]{2}{*}{$\mathrm{O}_{1} \mathrm{P}$} & MF-13 & 2.34 & 0.62 & 1.34 & 3 & 0.623 & 0.026 & 0.028 & 3 \\
\hline & MF-13 & 2.41 & 1.27 & 1.62 & 4 & 1.043 & 0.027 & 0.321 & 4 \\
\hline \multirow[t]{2}{*}{$\mathrm{O}_{1-2} \mathrm{Y}$} & MF-13 & 3.22 & 1.42 & 2.32 & 2 & 1.221 & 0.007 & 0.614 & 2 \\
\hline & MF-13 & 3.36 & 1.61 & 2.48 & 2 & 0.823 & 0.003 & 0.413 & 2 \\
\hline \multirow[t]{3}{*}{$\mathrm{O}_{1} \mathrm{P}$} & MF-14 & 4.22 & 1.46 & 3.23 & 4 & 2.104 & 0.012 & 0.732 & 4 \\
\hline & MF-14 & 6.42 & 1.32 & 4.01 & 3 & 2.043 & 0.028 & 0.513 & 3 \\
\hline & MF-14 & 5.26 & 1.56 & 3.13 & 3 & 2.143 & 0.021 & 0.435 & 3 \\
\hline \multirow[t]{2}{*}{$\mathrm{O}_{1-2} \mathrm{Y}$} & MF-14 & 5.62 & 2.02 & 3.12 & 4 & 1.144 & 0.041 & 0.701 & 4 \\
\hline & MF-14 & 7.21 & 1.63 & 3.54 & 4 & 2.312 & 0.043 & 0.812 & 4 \\
\hline \multirow[t]{2}{*}{$\mathrm{O}_{1} \mathrm{P}$} & MF-15 & 4.13 & 2.31 & 3.42 & 3 & 1.611 & 0.032 & 0.142 & 3 \\
\hline & MF-15 & 3.81 & 1.11 & 2.01 & 4 & 1.512 & 0.084 & 0.432 & 4 \\
\hline \multirow[t]{2}{*}{$\mathrm{O}_{1-2} \mathrm{Y}$} & MF-15 & 5.43 & 1.22 & 2.42 & 5 & 1.519 & 0.025 & 0.532 & 5 \\
\hline & MF-15 & 6.01 & 1.51 & 2.35 & 4 & 2.012 & 0.067 & 0.951 & 4 \\
\hline \multirow[t]{2}{*}{$\mathrm{O}_{1} \mathrm{P}$} & MF-16 & 2.73 & 1.35 & 2.04 & 2 & 1.734 & 0.052 & 0.892 & 2 \\
\hline & MF-16 & 3.13 & 1.51 & 5.43 & 5 & 2.022 & 0.064 & 0.911 & 5 \\
\hline \multirow[t]{2}{*}{$\mathrm{O}_{1-2} \mathrm{Y}$} & MF-16 & 3.24 & 1.24 & 4.74 & 4 & 1.464 & 0.052 & 0.421 & 4 \\
\hline & MF-16 & 4.21 & 1.45 & 2.83 & 2 & 1.871 & 0.051 & 0.961 & 2 \\
\hline \multirow[t]{2}{*}{$\mathrm{O}_{1} \mathrm{P}$} & MF-17 & 2.81 & 0.93 & 1.25 & 3 & 0.533 & 0.024 & 0.227 & 3 \\
\hline & MF-17 & 2.32 & 1.21 & 1.77 & 2 & 0.744 & 0.023 & 0.384 & 2 \\
\hline \multirow[t]{2}{*}{$\mathrm{O}_{1-2} \mathrm{Y}$} & MF-17 & 2.53 & 1.12 & 1.83 & 2 & 0.424 & 0.035 & 0.229 & 2 \\
\hline & MF-17 & 2.14 & 1.23 & 1.44 & 4 & 0.723 & 0.031 & 0.432 & 4 \\
\hline
\end{tabular}

MF-1 to MF-17: carbonate microfacies; $\mathrm{O}_{1} \mathrm{P}$ : Penglaiba formation; $\mathrm{O}_{1-2} \mathrm{Y}$ : Yingshan formation; Freq.: frequency

and MF-17 (1.64\%) and $\left(0.331 \times 10^{-3} \mathrm{mD}\right)($ Fig. 10a-h). There exists a weak positive relationship in the cross-plot of the average porosity and permeability of the seventeen microfacies (MF-1 to MF-17) samples from the Penglaiba and Yingshan Formations. This relationship probably reflects similar evolutionary patterns and/or development conditions for the hydrocarbon reservoirs (Fig. 10i).

\section{Hydrocarbon reservoir pore space types and characteristics}

The hydrocarbon reservoir spaces in the high-energy reef and shoal facies of the Lower Ordovician $\mathrm{O}_{1} \mathrm{P}$ and $\mathrm{O}_{1-2} \mathrm{Y}$ were identified and analyzed by the use of core logs and apoxy pore-cast thin-section data. The primary porosity of these high-energy reef and shoal carbonate facies was extensively reduced by the effect of compaction and cementation during burial. However, the pores that contained hydrocarbon within them at the early stage of the rock's history were presumably preserved, implying that most of the pore space types in this study are of secondary origin (Figs. 6a-c, $h$ and $7 \mathrm{a}-\mathrm{i})$.

The results of the analyzes of the high-energy reef and shoal carbonate reservoir spaces showed seven types of dissolved pore spaces, including pores along fractures, vesicular pores, tabular pores, intragranular solution pores, intergranular pores, vuggy/moldic pores and mottled pores (Figs. $6 \mathrm{a}-\mathrm{c}, \mathrm{h}$ and $7 \mathrm{a}-\mathrm{i}$ ). Intragranular solution pores, intergranular pores, tabular pores and vuggy/moldic pores are the most common reservoir pore spaces with pore sizes 

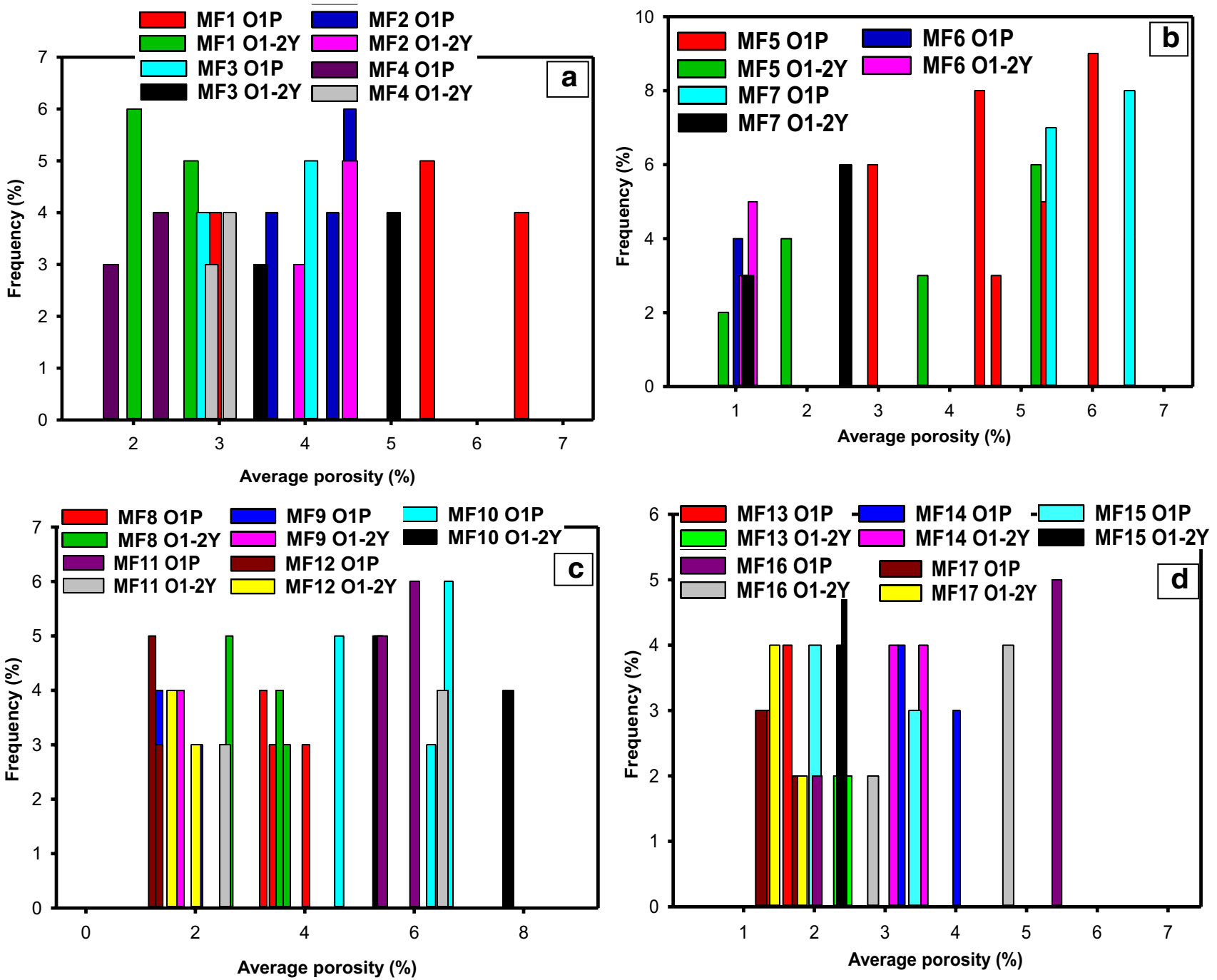

Fig. 10 Frequency distribution of average porosity and average permeability in the reef and shoal microfacies (MF-1 to MF-17) of the Lower Ordovician Formations in the Tazhong Uplift: a frequency histogram of average porosity of MF-1 to MF-4 in the $\mathrm{O}_{1} \mathrm{P}$ and $\mathrm{O}_{1-2} \mathrm{Y}$; b frequency histogram of average porosity of MF-5 to MF-7 in the $\mathrm{O}_{1} \mathrm{P}$ and $\mathrm{O}_{1-2} \mathrm{Y} ; \mathbf{c}$ frequency histogram of average porosity of MF-8 to MF-12 in the $\mathrm{O}_{1} \mathrm{P}$ and $\mathrm{O}_{1-2} \mathrm{Y}$; $\mathbf{d}$ frequency histogram of average porosity of MF-13 to MF-17 in the $\mathrm{O}_{1} \mathrm{P}$ and $\mathrm{O}_{1-2} \mathrm{Y}$; e frequency histogram of average permeability of MF-1 to MF-4 in the $\mathrm{O}_{1} \mathrm{P}$ and $\mathrm{O}_{1-2} \mathrm{Y}$; f frequency histogram of average permeability of MF-5 to MF- 8 in

ranging from 0.05 to $10 \mathrm{~mm}$ (Figs. $6 \mathrm{~b}, \mathrm{~h}$ and $7 \mathrm{~b}, \mathrm{e}, \mathrm{h}, \mathrm{i}$ ). Although some pore spaces are commonly filled with calcite spar, most of the effective reservoir spaces are commonly preserved.

Three types of fractures/fissures were observed in the high-energy reef and shoal facies, including solution-enlarged fractures, dissolved fissures/stylolites and low-medium-high-angle irregular horizontal fractures (Figs. 4g, 5a-f and 7c, d). The fracture networks and dissolved fissures/stylolites are the main reservoir spaces

the $\mathrm{O}_{1} \mathrm{P}$ and $\mathrm{O}_{1-2} \mathrm{Y} ; \mathbf{g}$ frequency histogram of average permeability of MF-9 to MF-12 in the $\mathrm{O}_{1} \mathrm{P}$ and $\mathrm{O}_{1-2} \mathrm{Y}$; $\mathbf{h}$ frequency histogram of average permeability of MF-13 to MF-17 in the $\mathrm{O}_{1} \mathrm{P}$ and $\mathrm{O}_{1-2} \mathrm{Y}$; $\mathbf{i}$ a weak positive relationship between average porosity and average permeability of the hydrocarbon reservoirs in the reef and shoal microfacies (MF-1 to MF-17) of the Lower Ordovician Formations in the Tazhong Uplift. This weak positive relationship in the cross-plot of the average porosity and average permeability probably reflects similar evolutionary patterns and/or development conditions for the hydrocarbon reservoirs

observed on most cores and thin sections. They usually have low- to medium-high-angle intersections and constitute good reservoir spaces and permeating channels. Dissolved fissures/stylolites appeared as serrated, curved or zigzag-shaped, mesh or reticular pores on the cores and thin sections, and are somewhat filled with calcite spar cements.

A few karst caves have circular shapes in most sand shoal facies, with others appearing as honeycombs and elongatedshaped strips along laminae and sometimes along fractures.

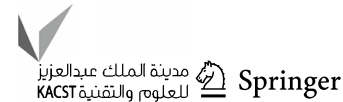



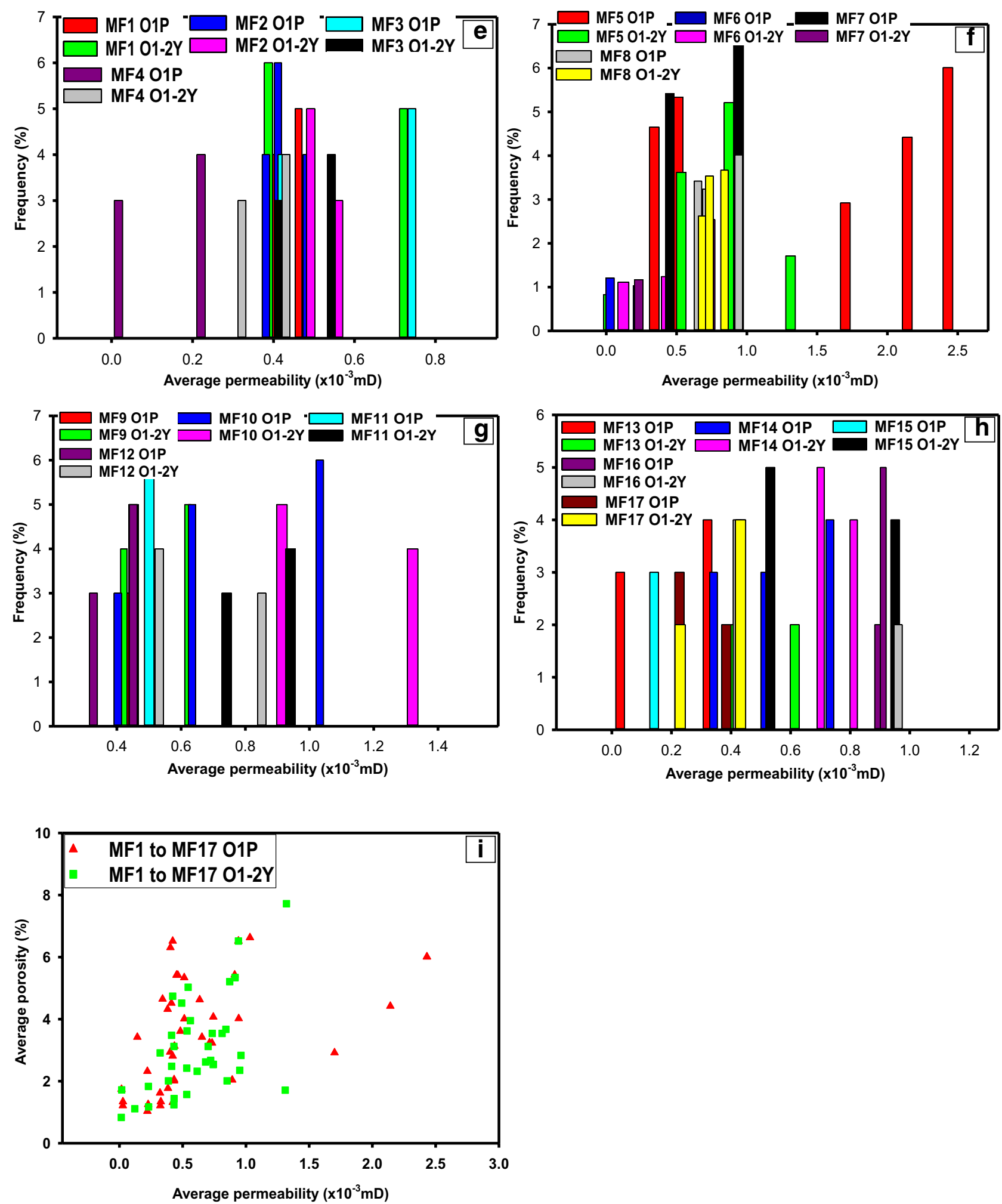

Fig. 10 (continued) 
Though calcite spar cements and organic matter partially or completely occludes the karst caves (Figs.4f and 7f), a considerable amount of effective reservoir spaces are present.

\section{Types of hydrocarbon reservoirs}

Three main types of hydrocarbon reservoirs were recognized in the high-energy reef and shoal facies of the $\mathrm{O}_{1} \mathrm{P}$ and $\mathrm{O}_{1-2} \mathrm{Y}$ and classed as follows:

\section{Type 1 reservoirs}

Type 1 reservoirs are associated with synsedimentary highenergy reef and sand shoal facies. These reservoir spaces are mainly composed of microporosity and include acicular intragranular pores $(0.05-3 \mathrm{~mm})$ within grains and tiny vesicular intercrystalline pores $(0.001-2 \mathrm{~mm})$, and pores between calcite cement crystals. They have been extensively reduced by the effect of compaction and cementation during burial diagenesis. The reservoirs are mainly distributed at the vicinity of the third-order sequence boundaries and bedding planes within the Penglaiba and Yingshan Formations, and their development is closely associated with the primary sedimentary facies and the sequence boundary (Fig. 3a, b).

\section{Type 2 reservoirs}

Type 2 reservoirs are developed by burial dissolution and tectonic activity. The dissolved vuggy/moldic pore spaces, solution-enlarged fractures/stylolites and tectonic fractures are the main reservoir spaces (Figs. 4g, 5a-f, 6a, b, c, h and $7 \mathrm{a}-\mathrm{i})$. Core observation revealed that some vuggy/moldic pores and fracture reservoirs are filled with geothermal/ hydrothermal minerals including lead-zinc mineralization, quartz and saddle dolomite, indicating that type 2 reservoirs were modified by multiphase tectonic activity (Zhong et al. 2010; Wu et al. 2012; Li et al. 2013a, b), and shallow to deep burial dissolution by mesogenetic fluids, geothermal/hydrothermal basinal fluids and TSR-related fluids (e.g., Mazzullo and Harris 1992; Worden and Smalley 1996; Cai et al. 2001, 2015a; Jin et al. 2009; Yang et al. 2012; Ehrenberg et al. 2012; Li et al. 2014; Jia et al. 2015; Zhu et al. 2017). The type 2 reservoirs are of secondary origin and constitute the main hydrocarbon reservoirs in the study area.

\section{Type 3 reservoirs}

Type 3 reservoirs are hypogenic-epigenetic karst reservoirs. These types of reservoirs are usually associated with karst breccias on the platform margin/marginal slopes and are mainly developed toward the topmost part of the SQ2 in the $\mathrm{O}_{1} \mathrm{P}$ and below the RUS2 unconformity surface (Fig. 3a, b). They are formed as a result of the high susceptible of the reef and shoal facies to widespread denudation due to a long-term exposure caused by relative sea-level drop (Lin et al. 2012), tectonic activity and dissolution (meteoric and mesogenetic) (Figs. 4f and 7f) (Gong and Liu 2003; Baryakh and Fedoseev 2011; Yang et al. 2011; Ehrenberg et al. 2012; Zhu et al. 2017). These aforementioned factors favored the development of hypogenic-epigenetic karst reservoirs in near-surface shallow burial settings. The type 3 reservoirs are of secondary origin and are the second major hydrocarbon reservoirs in the study area. Hence, the extensive uplift of Tarim block during the Late Permian (Li et al. 2008; Wu et al. 2012; Li et al. 2013a, b) could have been the main cause of the significant exposure to intense denudation and dissolution/karstification of the platform reef and shoal facies in the Tazhong Uplift. This interpretation is supported by the abundant distribution of hydrocarbon reservoirs in the vicinity of unconformities, third-order sequence boundaries, bedding planes, faults and related fracture networks.

In summary, the porosity and permeability of the coarsegrained microfacies in the HST of the third-order sequences (SQ1-SQ3) correlates well with the regression peaks in the $\mathrm{O}_{1} \mathrm{P}$ and $\mathrm{O}_{1-2} \mathrm{Y}$. Moreover, the generation of characteristic hydrocarbon reservoirs in the shallow to deeply buried reef and shoal carbonate facies in the study area by high-temperature active basinal dissolution fluids (mesogenetic fluids, geothermal/hydrothermal fluids and TSR-related fluids) is aided by faults and related fracture networks, stylolites, sequence boundary and other permeable horizons, which act as lateral and vertical migration pathways for these basinal dissolution fluids. The characteristic hydrocarbon reservoirs generated by these basinal dissolution fluids constitute relatively moderate-high-quality hydrocarbon reservoirs in the Lower Ordovician strata and are somewhat the potential reservoirs for hydrocarbon exploration in the Tazhong Uplift in central Tarim basin.

\section{Conclusions}

Based on detailed petrographic analysis of thin sections, cores and well logging data of the Lower Ordovician carbonate successions in the Tazhong Uplift in central Tarim basin, the following conclusions are drawn:

1. The analyses of hydrocarbon reservoirs in the high-frequency reef and shoal facies of the Lower Ordovician carbonate successions in the $\mathrm{O}_{1} \mathrm{P}$ and $\mathrm{O}_{1-2} \mathrm{Y}$ in Tazhong Uplift, central Tarim basin showed seven types of dissolved pore spaces, three types of fractures and karst caves. These hydrocarbon reservoirs are classified into three main types: type 1 associated with synsedimentary facies, type 2 developed by hot active basinal dissolution fluids (mesogenetic fluids, geothermal/hydrothermal flu-

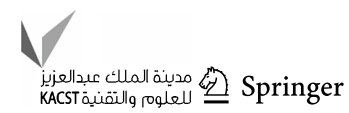


ids and TSR-related fluids) and tectonic activity, and type 3 are hypogenic-epigenetic karst reservoirs generated by dissolution fluids (meteoric and mesogenetic). The characteristic hydrocarbon reservoirs generated by these basinal dissolution fluids constitute relatively moderate-high-quality hydrocarbon reservoirs in the studied Lower Ordovician strata. Porosity and permeability development in the reef and shoal facies of the highstand system tracts (HST) of the third-order sequence cycles (SQ1-SQ3) correlates well with regression peaks in $\mathrm{O}_{1} \mathrm{P}$ and $\mathrm{O}_{1-2} \mathrm{Y}$.

2. The relatively low paleomicro-uplifts linked by intraplatform lows and microslopes, tectonics, and frequent relative sea-level fluctuation associated with rapid transgression and slow regression presumably favored the sedimentation of the large-scale cyclic vertical stack patterns of shallowing-upward reef and shoal facies across the carbonate platforms.

3. Six third-order depositional sequences (SQ1-SQ4) were identified in this study. Sequence SQ1 and SQ2 were identified in the Penglaiba Formation, and SQ1-SQ4 were recognized in the Yingshan Formation. These third-order depositional sequences are composed of asymmetrical and minor symmetrical sequence cycles, which form repeated shallowing-upward and coarsening-upward cycles. These sequence cycles reflect a short transgrassive phase and prolong marine regression due to upward increased in hydrodynamic energy from the TST to the HST.

4. Seventeen microfacies (MF-1 to MF-17) were identified within the Lower Ordovician carbonate successions of the Tazhong Uplift. These microfacies were distinguished based on their textures (grain sizes, shape and sorting), fossil contents and matrix contents. Six microfacies associations (MFA-1 to MFA-6) were identified based on their vertical stacking patterns and position in the depositional sequence. MFA-1 to MFA- 6 reflect a series of correlative depositional environments. Each type of microfacies in the association reflects a specific depositional environment under particular hydrodynamic conditions. These microfacies associations appear as shallowing-upward and coarsening-upward third-order sequence cycles that represent sedimentary facies such as subtidal-lagoon and tidal flat facies, silt to sand gravel shoal facies, and reef and sand shoal facies deposited in platform interior (restricted subtidal-intertidal platform, intraplatform shoal and open platform) and platform margin, respectively.

Acknowledgments This study was funded by the National Natural Science Foundation Project of China (Grant Nos. 41372126 and 41772103), and National Science and Technology Major Project of
China (Grant No. 2016ZX05007-002). We appreciate the constructive suggestions of Dr Deng Qingjie and Dr Sun Chun Yan during the preparation of this manuscript. The authors greatly appreciate the valuable comments and suggestions made by the Editor and reviewers that has helped to restructured this manuscript.

Open Access This article is licensed under a Creative Commons Attribution 4.0 International License, which permits use, sharing, adaptation, distribution and reproduction in any medium or format, as long as you give appropriate credit to the original author(s) and the source, provide a link to the Creative Commons licence, and indicate if changes were made. The images or other third party material in this article are included in the article's Creative Commons licence, unless indicated otherwise in a credit line to the material. If material is not included in the article's Creative Commons licence and your intended use is not permitted by statutory regulation or exceeds the permitted use, you will need to obtain permission directly from the copyright holder. To view a copy of this licence, visit http://creativecommons.org/licenses/by/4.0/.

\section{References}

Al-Awwad SF, Collins LB (2013) Carbonate-platform scale correlation of stacked high-frequency sequences in the Arab-D reservoir, Saudi Arabia. Sediment Geol 294:205-218

Baryakh AA, Fedoseev AK (2011) Sinkhole formation mechanism. J Min Sci 47(4):404-412

Cai CF, Hu WS, Worden RH (2001) Thermochemical sulphate reduction in Cambro-Ordovician carbonates in Central Tarim. Mar Pet Geol 18:729-741

Cai CF, Worden RH, Wang QH, Xiang TS, Zhu JQ, Chu XL (2002) Chemical and isotopic evidence for secondary alteration of natural gases in the Hetianhe Field, Bachu Uplift of the Tarim Basin. Org Geochem 33:1415-1427

Cai CF, Worden RH, Bottrell SH, Wang LS, Yang CC (2003) Thermochemical sulphate reduction and the generation of hydrogen sulphide and thiols (mercaptans) in Triassic carbonate reservoirs from the Sichuan basin, China. Chem Geol 202:39-57

Cai CF, Xie ZY, Worden RH, Hu GY, Wang LS, He H (2004) Methane-dominated thermochemical sulphate reduction in the Triassic Feixianguan Formation East Sichuan Basin, China: towards prediction of fatal H2S concentrations. Mar Pet Geol 21:1265-1279

Cai CF, Li KK, Li HT, Zhang BS (2008) Evidence for cross formational hot brine flow from integrated ${ }^{87} \mathrm{Sr} /{ }^{86} \mathrm{Sr}$, REE and fluid inclusions of the Ordovician veins in Central Tarim. Appl Geochem 23:2226-2235

Cai CF, Zhang CM, Cai LL, Wu GH, Jiang L, Xu ZM, Li KK, Ma AL, Chen LX (2009a) Origins of Palaeozoic oils in the Tarim basin: evidence from sulfur isotopes and biomarkers. Chem Geol 268:197-210

Cai CF, Li KK, Ma AL, Zhang CM, Xu ZM, Worden RH, Wu GH, Zhang BS, Chen LX (2009b) Distinguishing Cambrian from Upper Ordovician source rocks: evidence from sulfur isotopes and biomarkers in the Tarim Basin. Org Geochem 40:755-768

Cai CF, He WX, Jiang L, Li KK, Xiang L, Jia LQ (2014) Petrological and geochemical constraints on porosity difference between Lower Triassic sour and sweet-gas carbonate reservoirs in the Sichuan Basin. Mar Pet Geol 56:34-50

Cai CF, Hu GY, Li HX, Jiang L, He WX, Zhang BS, Jia LQ, Wang TK (2015a) Origins and fates of $\mathrm{H}_{2} \mathrm{~S}$ in the Cambrian and Ordovician in Tazhong area: evidence from sulfur isotopes, fluid inclusions and production data. Mar Pet Geol 67:408-418

Cai CF, Zhang CM, Worden RH, Wang TK, Li HX, Jiang L, Huang SY, Zhang BS (2015b) Application of sulfur and carbon 
isotopes to oil-source rock correlation: a case study from the Tazhong area, Tarim Basin, China. Org Geochem 83:140-152

Cai CF, Amrani A, Worden RH, Xiao QL, Wang TK, Gvirtzman Z, Li HX, Said-Ahmad W, Jia LQ (2016) Sulfur isotopic compositions of individual organosulfur compounds and their genetic links in the Lower Paleozoic petroleum pools of the Tarim Basin, NW China. Geochim Cosmochim Acta 182:88-108

Chen HL, Yang XF, Dong CW, Zhu GQ, Jia CZ, Wei GQ, Wang ZG (1997) Study of thermal events in Tarim basin. Chin Sci Bull 42:1096-1099

Chen GJ, Xue LH, Wang Q, Kang J, Xiao LX, Shi J (1999) Sea level changes and formation of cyclic-sequence of CambrianOrdovician in Akesu-Bachu area, Xinjiang. Acta Sedimentol Sin 17:192-197

Chen BC, Xie XN, Al-Aasm IS, Wu F, Zhou M (2018) Depositional Archetecture and Facies of a complete Reef complex succession: a case study of the Permian Jiantianba Reefs, Western Hubei, South China. Minerals 8:533. https://doi.org/10.3390/ $\min 8110533$

Dong S, Chen D, Zhou X, Qian Y, Mi T, Qing H (2016) Tectonically-driven dolomitization of Cambrian to Lower Ordovician carbonates of the Quruqtagh area, north-eastern flank of Tarim Basin, north-west China. Sedimentology. https://doi.org/10.1111/ sed. 12341

Dunham RJ (1962) Classification of carbonate rocks according to depositional texture. In: Ham WE (ed) Classification of carbonate rocks. American Association of Petroleum Geologists Memoir, Tulsa, pp 108-121

Ehrenberg SN, Walderhaug O, Bjorlykke K (2012) Carbonate porosity creation by mesogenetic dissolution: Reality or illusion? AAPG Bull 96(2):217-233

Embry AF, Klovan JE (1971) A late Devonian reef tract on northeastern Banks Islands, Northwest Territories. Bull Can Pet Geol 19:730-781

Eugene CR, Bernhard DR, Kelley S (2006) Form, function and feedbacks in a tidally dominated ooid shoal, Bahamas. Sedimentology 53:1191-1210

Fan TL, Yu BS, Gao ZQ (2007) Characteristics of carbonate sequence stratigraphy and its control on oil-gas in Tarim basin. Geoscience 21:57-65

Feng ZZ, Bao ZD, Wu MB, Jin ZK, Shi XZ, Luo AR (2007) Lithofacies palaeogeography of the ordovician in Tarim area. J Palaeogeogr 9(5):447-460

Flügel E (2004) Microfacies of carbonate rocks. Springer, Berlin

Fu H, Hao JH, Meng WB, Feng MS, Hao L, Gao YF, Guan YS (2017) Forming mechanism of the Ordovician karst carbonate reservoirs on the northern slope of central Tarim basin. Nat Gas Ind B 4(4):294-304

Gao Z, Fan T (2014a) Intra-platform tectono-sedimentary response to geodynamic transition along the margin of the Tarim Basin, NW China. J Asian Earth Sci 96:178-193

Gao ZQ, Fan TL (2014b) An early Paleozoic inter-platform shelf in the Southwest of Tarim Basin, NW China and its significance for petroleum exploration. Resour Geol 64(4):346-366

Gao ZQ, Fan TL (2015) Unconformities and their influence on lower Paleozoic petroleum reservoir development in the Tarim Basin. $\mathrm{J}$ Pet Sci Eng 133:335-351

Gao Z, Tailiang F (2015) Carbonate platform-margin architecture and its influence on Cambrian-Ordovician reef and shoals development, Tarim Basin, NW China. Mar Pet Geol 68:291-306

Gao ZQ, Fan TL (2013) Ordovician intra-platform shoal reservoirs in the Tarim Basin, NW China: characteristics and depositional controls. Bull Can Pet Geol 61(1):83-100

Gao ZQ, Fan TL, Wang HM (2005) The developmental conditions and distributional rules of the reef-shoal reservoirs in Central Tarim Basin. Xinjiang Geol 23(3):283-287
Gao D, Changsong L, Haijun Y, Fanfan Z, Zhenzhong C, Lijuan Z, Jingyan L, Hong L (2014) Microfacies and depositional environments of the late Ordovician Lianglitage Formation at the Tazhong Uplift in the Tarim basin of Northwest China. J Asian Earth Sci 83:1-12

Gertsch B, Keller G, Adatte T, Berner Z, Kassab AS, Tantawy AA, El-Sabbagh AM, Stueben D (2010) Cenomanian-Turonian transition in a shallow water sequence of the Sinai, Egypt. Int J Earth Sci 99:165-182

Gong F, Liu X (2003) Controlling effects of faults over palaeokarst in west Lungu region Tarim basin. Carsol Sin 22(4):313-317

Gonzales R (1996) Response of shallow-marine carbonate facies to third-order and high-frequency sea level fluctuations: Hauptrogenstein Formation, northern Switzerland. Sediment Geol 102:111-130

Gu J (2001) The significance of Ordovician Reef discovery in Tarim basin. Pet Explor Dev 28(4):1-3

Guo C, Daizhao C, Hairuo Q, Shaofeng D, Guorong L, Dan W, Yixiong Q, Cunge L (2016) Multiple dolomitization and later hydrothermal alteration on the Upper Cambrian-Lower Ordovician carbonates in the northern Tarim Basin, China. Mar Pet Geol 72:295-316

Hendry JP, Gregg JM, Shelton KL, Somerville ID, Crowley SF (2015) Origin, characteristics and distribution of fault-related and fracture-related dolomitization: insights from Mississippian carbonates, Isle of Man. Sedimentology 62:717-752

Hu MY, Wu Y, Zhonggui H, Qian Y, Xiang J (2009) Deep buried dissolution of Ordovician carbonates in Tazhong Area of Tarim Basin. J Oil Gas Technol 31(6):49-54

Hu MY, Ngia NR, Gao D (2019) Dolomitization and hydrotectonic model of burial dolomitization of the Furongian-Lower Ordovician carbonates in the Tazhong Uplift, central Tarim Basin, NW China: Implications from petrography and geochemistry. J Mar Pet Geol. https://doi.org/10.1016/j.martpetgeo.2019.04.018

Jia L, Cai C, Yang H, Li H, Wang T, Zhang B, Jiang L, Tao X (2015) Thermochemical and bacterial sulfate reduction in the Cambrian and Lower Ordovician carbonates in the Tazhong Area, Tarim Basin, NW China: evidence from fluid inclusions, C, S, and $\mathrm{Sr}$ isotopic data. Geofluids 15:421-437

Jia LQ, Cai C, Li HX, Wang TK, Zhang W, Kong LW (2016) Thermochemical Sulfate Reduction-related Mesogenetic Dissolution of Deeply Buried Dolostone Reservoirs in the Tazhong Area. Acta Sedimentol Sin 34(6): 1057-1067

Jianfa H, Hao L, Xiaoyong H, Qinglong W, Yubin S (2015) Characteristics of Ying Shan formation carbonate sequence stratigraphy in middle of the Tarim basin. In: International power, electronics and materials engineering conference (IPEMEC)

Jiang L, Pan WQ, Cai CF, Jia LQ, Pan LY, Wang TK, Li HX, Chen SL, Chen Y (2015) Fluid mixing induced by hydrothermal activity in the Ordovician carbonates in Tarim Basin, China. Geofluids 15:483-498

Jiang L, Cai CF, Worden RH, Crowley SF, Jia L, Zhang K, Duncan IJ (2016) Multiphase dolomitization of deeply buried Cambrian petroleum reservoirs, Tarim Basin, north-west China. Sedimentology. https://doi.org/10.1111/sed.12300

Jin Z, Zhu D, Hu W, Zhang X, Zhang J, Song Y (2009) Mesogenetic dissolution of the middle Ordovician limestone in the Tahe oilfield of Tarim basin, NW China. Mar Pet Geol 26:753-763

Jing X (2009) The Ordovician Condonts and the Cambrian-Ordovician boundary at the platform facies in the Tarim Basin. China University of Geosciences, Beijing

Lan XD, Lü XX, Zhu YM, Yu HF, Zhou J, Zhu F (2013) Characteristics and differential accumulation of oil/gas in Lower Paleozoic marine carbonate on northern slope of Tazhong Low Rise, Tarim Basin, NW China: a case study of Lower Ordovician Yingshan Formation. Arab J Geosci 10:1-12

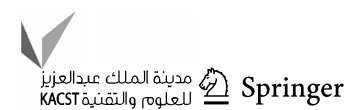


Li H, Cai C (2017) Origin and evolution of formation water from the Ordovician carbonate reservoir in the Tazhong area, Tarim basin, NW China. J Petroleum Sci Eng 148:103-114

Li DS, Liang DG, Jia CZ, Wang G, Wu QZ, He DF (1996) Hydrocarbon accumulations in the Tarim basin, China. AAPG Bull 80:1587-1603

Li Y, Wu G, Meng Q, Yang H, Han J, Li X, Dong L (2008) Fault system in central area of the Tarim basin: geometry, kinematics and dynamic settings. Chin J Geol 43:82-118

Li H, Lin CS, Zhang YM, Zhang RX, Rui ZF, Huang L (2012) Stratigraphic architecture and computer modeling of carbonate platform margin, late Ordovician Lianglitage Formation, Central Tarim basin. J Earth Sci. https://doi.org/10.1007/s1258 3-012-0279-9

Li C, Wang X, Li B, He D (2013a) Paleozoic fault systems of the Tazhong Uplift, Tarim basin. China Mar Pet Geol 39(1):48-58

Li Y, Bai X, Su B, Yuan X, Liu D (2013b) Sedimentary facies and depositional model of middle-lower ordovician yingshan formation in Tazhong area. Reserv Eval Dev 3(1):1-8

Li KK, Cai CF, Jia LQ, Gao Y, Jiang Z, Wang TK, Jiang L (2014) The role of thermochemical sulfate reduction in the genesis of highquality deep marine reservoirs within the central Tarim basin, western China. Arab J Geosci 8:1-14

Li Q, Zaixing J, Wenxuan H, Xuelian Y, Guoli H, Juntao Z, Xiaolin W (2016) Origin of dolomites in the Lower Cambrian Xiaoerbulak Formation in the Tarim basin, NW China: implications for porosity development. J Asian Earth Sci 115:557-570

Lin CS, Yang HJ, Liu JY, Peng L, Cai ZZ, Yang XF, Yang YH (2009) Paleostructural geomorphology of the Paleozoic central uplift belt and its constraint on the development of depositional facies in the Tarim Basin. Sci China Ser D Earth Sci 52(6):823-834

Lin CS, Yang HJ, Liu JY, Rui ZF, Cai ZZ, Li ST (2012) Sequence architecture and depositional evolution of the Ordovician carbonate platform margins in the Tarim basin and its response to tectonism and sea-level change. Basin Res 24:559-582

Liu J, Wu J, Hou F, Zhu X (2006) Cambrian-Ordovician carbonate platform sedimentary system and its petroleum accumulation conditions in middle Tarim Upheaval. Mar Geol Lett 22(3):27-33

Mazzullo SJ, Harris PM (1992) Mesogenetic dissolution: its role in porosity development in carbonate reservoirs. AAPG Bull 76:607-620

Ngia NR, Hu MY, Gao D (2019) Tectonic and geothermal controls on dolomitization and dolomitizing fluid flows in the CambrianLower Ordovician carbonate successions in the western and central Tarim basin, NW China. J Asian Earth Sci 172:359-382

Sfidari E, Kadkhodaie-Ilkhchi A, Rahimpour-Bbonab H, Soltani B (2014) A hybrid approach for lithofacies characterization in the framework of sequence stratigraphy: a case study from the South Parsgas field, the Persian Gulf basin. J Pet Sci Eng 121:87-102

Tan XC, Liu XG, Chen JS, Liu H, Wu XQ, Qiu WB (2009) Shoal development within the epicontinental carbonate platform, Jia 2 Member, lower Triassic, Moxi gas field, central Sichuan Basin (in Chinese). Acta Sediment Sin 27:995-999

Wang ZM, Xie HW, Chen YQ, Qi YM, Zhang K (2014) Discovery and exploration of Cambrian Subsalt Dolomite Original Hydrocarbon Reservoir at Zhongshen-1 Well in Tarim Basin. China Petrol Explor 19:1-13

Wilson JL (1975) Carbonate facies in geologic history. Springer, New York

Worden RH, Smalley PC (1996) $\mathrm{H}_{2}$ S-producing reactions in deep carbonate gas reservoirs: Khuff Formation, Abu Dhabi. Chem Geol 133:157-171
Wu GH, Yang HJ, Qu TL, Li HW, Luo CS, Li BL (2012) The fault system characteristics and its controlling roles on marine carbonate hydrocarbon in the Central uplift Tarim basin. Acta Pet Sin 28(3):793-805

Yang XF, Lin CS, Yang HJ, Yang HJ, Han JF, Liu JY, Zhang YM, Peng L, Jing B, Tong JY, Wang HP, Li HP (2010) Depositional architecture of the late Ordovician drowned carbonate platform margin and its responses to sea-level fluctuation in the northern slope of the Tazhong region, Tarim basin. Pet Sci 7:323-336

Yang HJ, Zhu GY, Han JF, Wu FF, Ji YG, Su J, Zhang HZ, Wang Y (2011) Conditions and mechanism of hydrocarbon accumulation in large reef-bank karst oil/gas fields of Tazhong area, Tarim basin. Acta Pet Sin 27:1865-1885

Yang HJ, Li KK, Pan WQ, Xiao ZY, Cai CF (2012) Burial hydrothermal dissolution fluid activity and its transforming effect on the reservoirs in Ordovician in Central Tarim. Acta Pet Sin 28(3):783-792

Zhang ZS, Liu SP (1995) Sequence stratigaphy analysis of carbonate series of lower Palaeozoic group in the Tarim basin. Oil Geophys Prospect 30(2):245-256

Zhang LJ, Li Y, Zhou CG, Li M, Han J, Zhang B (2007) Lithofacies paleogeographical characteristics and reef and shoals distribution during the Ordovician in the Tarim basin. Oil Gas Geol 28(6):731-737

Zhang J, Hu W, Qian Y, Wang X, Cao J, Zhu J, Li Q, Xie X (2009) Formation of saddle dolomites in Upper Cambrian carbonates, western Tarim Basin (northwest China): implications for faultrelated fluid flow. Mar Petrol Geol 26:1428-1440

Zhao ZJ, Zhao ZX, Huang ZB (2006) Ordovician conodont zones and depositional sequences of Tarim basin. J Strat 30(3):193-202

Zhao ZJ, Zhou X, Wang Z, Shen A (2007) Distribution of marginal facies and main controlling factors of reservoirs in the Ordovician, the Tarim basin. Oil Gas Geol 28(6):738-744

Zhao WZ, Shen AJ, Hu SY, Pan WQ, Zheng JF, Qiao ZF (2012) Types and distributional features of Cambrian-Ordovician dolostone reservoirs in Tarim basin, northwestern China. Acta Pet Sin 28(3):758-768

Zhao WZ, Shen AJ, Pan WQ, Zhang BM, Qiao ZF, Zheng JF (2013) $A$ research on carbonate karst reservoirs classification and its implication on hydrocarbon exploration: cases studies from Tarim Basin. Acta Pet Sin 29(9):3213-3222

Zhong L, Sijing H, Jiaqing L, Chunfang C, Yuejun L (2010) Buried diagenesis, structurally controlled thermal fluid process and their effect on Ordovician carbonate reservoirs in Tahe Tarim basin. Acta Sedimentol Sin 28(5):969-979

Zhu DY, Meng Q, Jin ZJ, Liu QY, Hu WX (2015) Formation mechanism of deep Cambrian dolomite reservoirs in the Tarim Basin, northwestern China. Mar Pet Geol 59:232-244

Zhu HT, Zhu X, Chen HH (2017) Seismic characterization of hypogenic karst ayastems associated with deep hydrothermal fluids in the Middle-Lower Ordovician Yingshan Formation of the Shunnan area, Tarim basin NW China. Geofluids. https://doi. org/10.1155/2017/8094125

Publisher's Note Springer Nature remains neutral with regard to jurisdictional claims in published maps and institutional affiliations. 